\title{
How did women's education and differential family planning policies shape transition to second and third births in historical China? New evidence from micro data
}

\author{
Min Qin ${ }^{1,2}$ (D) Sabu S. Padmadas ${ }^{4}$ Jane Falkingham ${ }^{3}$
}

Received: 30 November 2021 / Accepted: 12 January 2022 / Published online: 11 February 2022

(c) The Author(s) 2022

\begin{abstract}
The influence of China's family planning policies on fertility transition is widely acknowledged in research studies. However, little is known about how improvements in women's education have shaped reproductive decisions of Chinese women across different family planning regimes, particularly at micro level. This study uses retrospective pooled birth history data from five consecutive population and family planning surveys collected over the period 1982-2006 to systematically examine the interrelationship between family planning policies and women's education, and their interactive effect on the second and third birth transitions. We hypothesize that family planning policies had a differential influence on educational groups in reducing the transition to second and third births. The results from discrete time complementary log-log survival models provide strong evidence of differential reproductive behavior of education groups across time in China, and the simultaneous influence of women's education and family planning policies in lowering risks to higher parities. The rates of progression to second and third births tend to be lower after the introduction of rigid family planning policies, and more importantly, the policy impact persisted even after adjusting for demographic and socioeconomic factors. The increase in women's education overall had a depressing effect on transition to higher parities, and family planning policies implemented overtime have had differential effects on women from different educational groups. The findings show that both family planning policies and women's education have been instrumental in shaping fertility behavior in China.
\end{abstract}

Keywords Family planning policies · China $\cdot$ Women's education $\cdot$ Second birth · Log-log survival analysis $\cdot$ Micro birth history data

Min Qin

mq1e12@soton.ac.uk

Extended author information available on the last page of the article 


\section{Introduction}

The underlying pathways through which women's education accelerates fertility decline in transitional and post-transitional societies have been widely researched (Behrman, 2015; Basu, 2002; Cleland, 2002; Cleland \& Rodriguez, 1988; Cochrane, 1979; Drèze \& Murthi, 2001; Jeffrey \& Basu, 1996; Jejeebhoy, 1995; Martin \& Juárez, 1995; Mason, 1987; Niu \& Qi, 2019; Smith, 1989). Women's education is an important socioeconomic marker and has been shown to have a measurable effect on reproductive decisions and fertility control, enabling women or couples to postpone marriage, space and limit births through the effective use of modern contraception (Bongaarts \& Potter, 1983). Education has an influential role in determining a woman's social and economic status, and her reproductive decisions and fertility behavior (Basu, 2002; Mason, 1987). There is a plethora of evidence highlighting the application of theories of economic and demographic transition, innovation-diffusion and social interactions, stressing the positive role of education in increasing contraceptive use and promoting small family norms at the individual and community levels (Bongaarts \& Watkins, 1996; Bongaarts, 2003; Caldwell, 1980; Casterline, 2001; Cleland \& Wilson, 1987; Colleran et al., 2014; Joshi \& Schultz, 2013; James et al., 2012; Jejeebhoy, 1995; Kravdal, 2002; Kirk, 1996; Martin, 1995; United Nations, 1995).

The education effect on fertility appears more pronounced in countries with conducive family planning and healthcare policies and program interventions (Bongaarts, 1994). In Southeast and East Asian countries including South Korea, Singapore, Hong Kong, Taiwan and Thailand, investment in women's education and effective family planning had a synergistic effect in accelerating economic development and reducing population growth (Bulatao, 1998; Robinson \& Ross, 2007). The most populous countries-China and India, on the other hand, opted for intensified state-administered family planning programs over social interventions for controlling their burgeoning population growth.

There is an extensive documentation of the historical evolution and impact of China's family planning policies on fertility decline (Attané, 2002; Feeney \& Yuan, 1994; Feeney \& Wang, 1993; Gu et al., 2007; Hardee-Cleaveland \& Banister, 1988; Hesketh et al., 2005; Merli \& Smith, 2002; Poston \& Gu, 1987; Qin et al., 2018; Retherford et al., 2005; Tien, 1984). However, there is relatively little research evidence on how women's education shaped the reproductive strategies and fertility behavior of Chinese women across different family planning regimes, especially at the micro level. This research addresses this gap by systematically investigating the mediating influence of family planning policies and education on the transition to second and third births over the period 1982-2006, and further examining whether family planning policies have differential effect on educational groups over time. Two key questions arise in the context of Chinese family planning policies implemented during this period. How did women with different levels of education and parity status respond to family planning policies in China? What is the underlying influence of female education in determining the transition towards second and third births in China over different family planning 
policy regimes? We hypothesize that (i) family planning policies implemented over time had differential influence on educational groups in reducing the risk to second and third birth transitions and (ii) there is an inverse relationship between women's education and parity transition.

The paper is structured in the following format. First, we review the existing evidence on the association between education and fertility and describe the Chinese context reflecting on major changes in official family planning policies, investment in education and reproductive behaviors. Then we discuss the data and methods including a description of birth history data from five consecutive population and family planning surveys. The findings from statistical analysis are presented in the next section and the paper concludes with a discussion on the key findings and implications for future population and family planning policies.

\section{Pathways linking education and fertility transition}

Theoretically, fertility in any society is determined by socioeconomic, environmental and policy factors which operate through a set of intermediate variables or proximate determinants (Bongaarts \& Potter, 1983). Globally, demographic data have shown considerable variation in fertility rates among women from various socioeconomic groups within and between regions and countries. Fertility is generally higher in rural than in urban areas and cities, higher among uneducated women and lower incomes groups (United Nations, 1987). Education is often used as a proxy indicator for opportunity costs and women's status to explain reproductive behaviors (Jejeebhoy, 1995; Mason, 1987).

Demographic transition and innovation-diffusion theories agree on the point that education has a major role in reducing fertility levels (Cleland \& Wilson, 1987; Notestein, 1953). Empirical evidence has shown that the level of female education is usually associated with lower fertility at both macro and micro levels (Bongaarts, 2003; Caldwell, 1980; Cleland, 2002; James et al., 2012; Martin, 1995; United Nations, 1987). The underlying mechanisms through which education influences reproduction can be explained by its effect on increasing age at marriage and contraceptive use, lowering the demand for children and reinforcing individual choices regarding family formation decisions (United Nations, 1995). In addition, education empowers women in terms of knowledge, decision-making, and control over economic and household resources, which in turn not only enhance women's well-being but also enable her with control over better reproductive decisions (Jejeebhoy, 1995). However, education and other individual socioeconomic drivers of fertility are conditioned by socioeconomic development, social structure and cultural context, which tend to change over the course of a demographic transition. Cleland (2002) argued that in most societies, fertility differences by levels of education should narrow over time and converge at the end of demographic transition. By contrast, Bongaarts (2003) in an empirical analysis found that fertility differentials by education remain significant even in post-transitional countries. 


\section{Fertility transition in the Chinese context}

At sub-region level or county level, there is evidence to suggest that education has had no noticeable effect and, overall, socioeconomic factors have played only a limited role (Bongaarts \& Greenhalgh, 1985; Retherford et al., 2005). However, other scholars argued that the observed decline in fertility levels should be attributed to both family planning policies and socioeconomic development (Cai, 2010; Poston, 2000; Poston \& Gu, 1987; Tien, 1980; Yang \& Chen, 2004). During the 1970s and 1980s, socioeconomic development in China was mainly characterized by modernization especially the development of coastal cities and urban development including transportation, infrastructure and opportunities for domestic and foreign investment (Perkin \& Yusuf, 1984; Yeung \& Hu, 1992). By the end of the 1970s, China had already achieved massive social transformation through a large expansion of primary education systems, social entrepreneurship, land reforms and rural health financing and cooperative systems (Liu et al., 1995; Tsang, 2000; Xing-Yuan \& Tang, 1995). Despite some challenges during the Cultural Revolution and post-Mao reforms, female education levels increased considerably between 1950s and 1958 and subsequently during late 1960s to mid-1970s (Lavely et al., 1990; Liu, 1994).

There is little systematic micro level evidence on the relationship between education and fertility in China. Aggregate data often have limited explanatory power to explain the causal effects underlying the relationship between policies and fertility and the mediating influence of socioeconomic factors, because they might not capture the heterogeneity of individual traits and relationships. A multilevel analysis using aggregated census and mini-census data between 1982 and 2015 found a negative association between women's education and the successive parity progression ratios in China, both during and after the fertility transition. The strength of the relationship varies over time and depends on the contextual features (Niu \& Qi, 2019). A micro econometric analysis of socioeconomic determinants of fertility in China, based on a fertility survey conducted in 1985, showed evidence of a J-shaped relationship between education and fertility amongst women aged 25-34 years (Zhang, 1990). However, existing constructs of family planning policy measures implemented over time in China had several limitations in terms of incompleteness, endogeneity, and randomness (Wang, 2012).

Since the 1970s, family planning policies in China have been decreed as institutional arrangements and specific programs through which the government systems exercised control over individual reproductive choices and fertility behavior. Previous studies have highlighted the underpinning strong influence of family planning policies on fertility in China (Chen et al., 2009; Feeney \& Wang, 1993; Feeney \& Yu, 1987; Retherford et al., 2005; Tien, 1984; Yang \& Chen, 2004). The evolution of family planning policies and its impact on fertility change at a macro level has been documented elsewhere (Qin et al., 2018).

It is important to address the typology of family planning policies (hereafter FPP) and changes in total fertility rates (TFR) under each alternative policy regime. FPP in China can be broadly categorized into three key phases. The first 
phase was 'later, longer, fewer FPP' (1973-1979); the second phase was 'one child FPP' (1979-1984); the third phase (1985-2015) of differentiated FPP further sub-divided into three types based on the number of children allowed per couple: or in TFR terms 'one child', 'one and half' and 'two' children'. The period and features of each policy, along with the provinces covered and the associated population coverage is illustrated in Table 1. Fertility in China declined rapidly from more than 6 in the beginning of 1970s, reaching replacement level in early 1990s, to well below replacement in the last two decades. This outcome is largely attributable to the effect of 'later, longer, fewer' FPP and the subsequent stricter family planning policies implemented by the Chinese government. The changes in parity-specific fertility under different FPP regimes implemented over time is illustrated in Fig. 1.

\section{Data and methodology}

Data Data for this study are drawn from retrospective pooled birth histories from a series of five consecutive population and family planning surveys collected over the period 1982-2006. The main purpose of these surveys was to generate data on fertility, contraceptive use and other reproductive health indicators. These surveys contain complete birth histories of women of reproductive ages (15-49 years) and the data were collected in 1982, 1988, 1997, 2001 and 2006 respectively, except for the 1992 survey where the birth histories of only the last four children were recorded. All surveys were designed to be nationally representative. Tibet was excluded in the 1982 and 2006 survey. For this study, we used data from the 1982, 1988, 1997, 2001 and 2006 surveys, excluding data on Tibet. A systematic assessment of the data confirmed quality and consistency in recording the dates of marriage and birth histories (Qin, 2016). Further details including the quality of data of these surveys are documented elsewhere (Feeney \& Wang, 1993; Feeney \& Yu, 1987; Feeney \& Yuan, 1994; Morgan et al., 2009).

Since the aim of the study was to examine the effect of FPP on the second and third birth transitions, we restricted our sample to participants who have had at least one child or two children. We employed discrete time survival models with timevarying and time-invariant covariates to analyze the timing and spacing of births. The unit of analysis was person-year and expanded samples of person-year observations were generated. Women who had a (first) birth were observed at various ages until the event of interest (second or third birth) or until the date of each survey. Note one individual can contribute to more than one observation. Table 2 shows the number of person-year observations for each survey.

Statistical modelling and analytical approach The outcome variables included the risks to transition to a second or third birth. Two separate discrete time complementary log-log survival models (CLL model) were specified with time measured from the previous birth, parity 1-2 and parity $2-3$. The risk or hazard $h(t)$ is the probability of occurrence of an event, conditional on survival and covariates, and time t; 


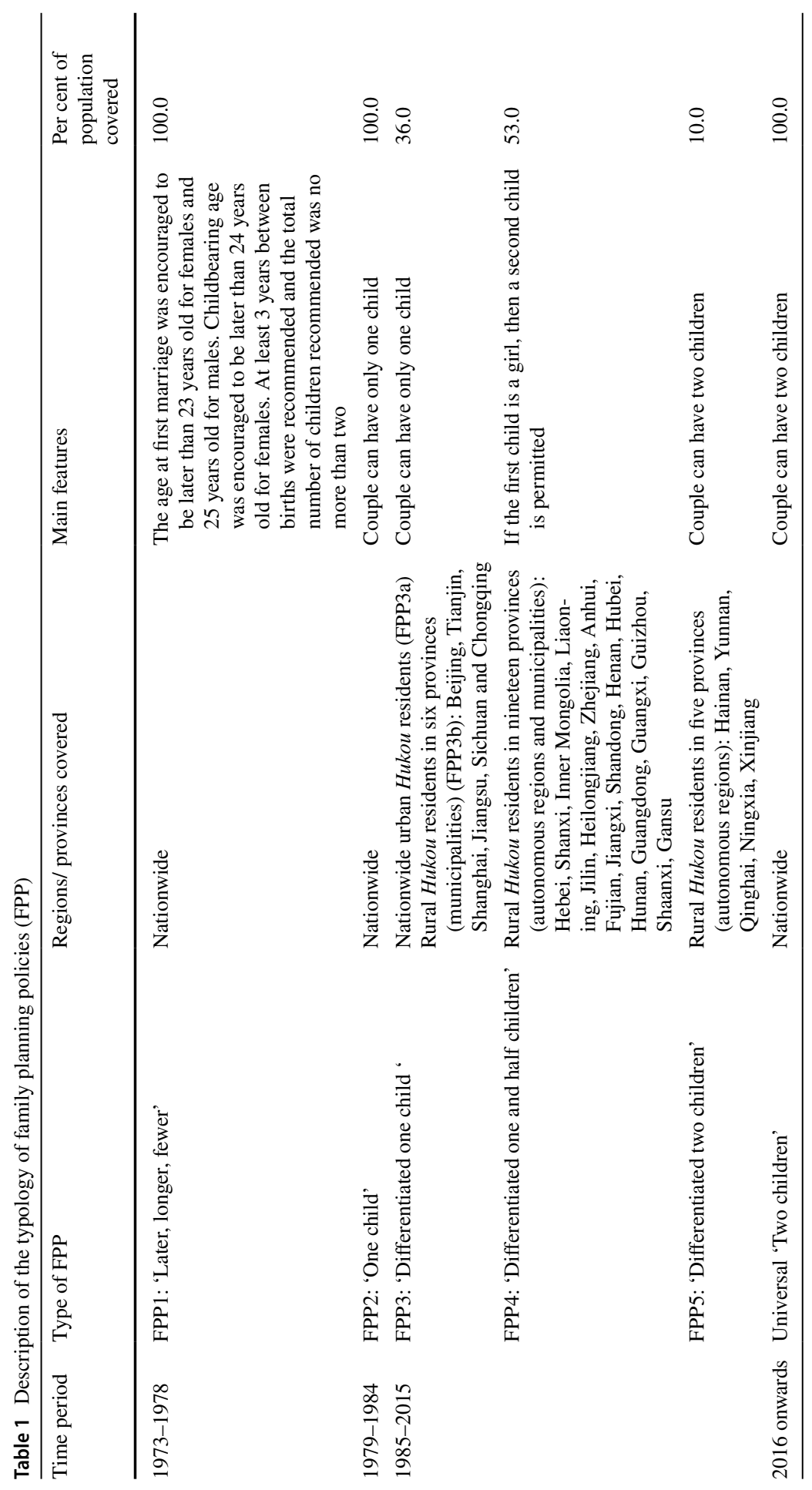




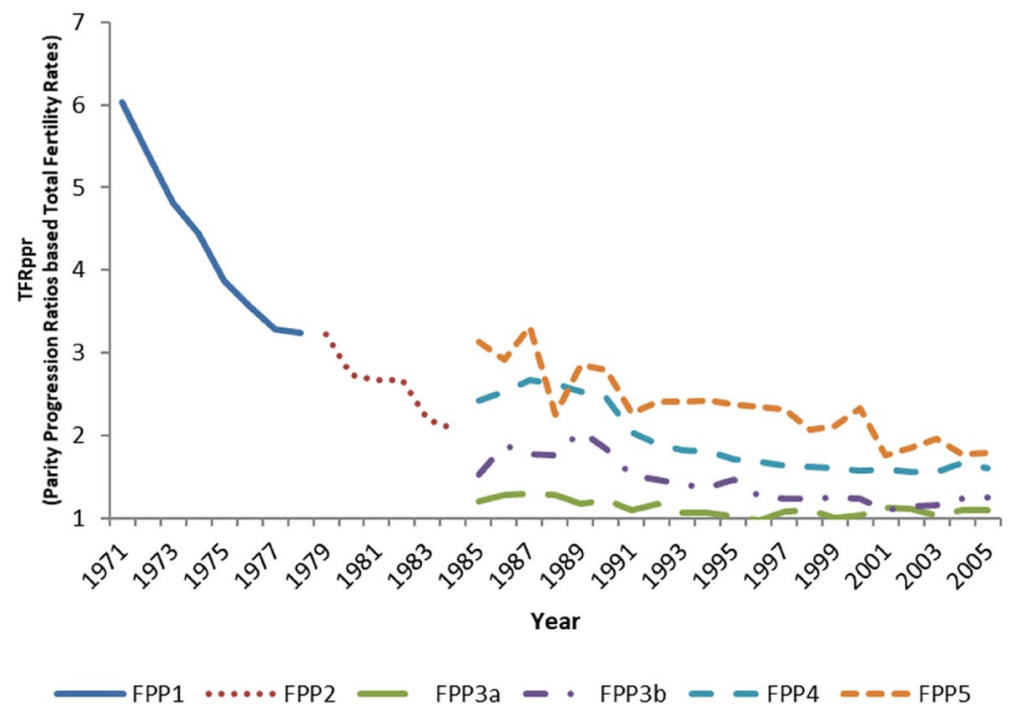

Fig. 1 TFRppr (Parity Progression Ratios based Total Fertility Rates) under the five alternative policy regimes, 1971-2005

Table 2 Number of personyears by parity transition among women aged $15-49$, various surveys

\begin{tabular}{llllll}
\hline Parity transition & \multicolumn{5}{l}{ Surveys } \\
\cline { 2 - 6 } & 1982 & 1988 & 1997 & 2001 & 2006 \\
\hline $1-2$ & 420,254 & $1,125,587$ & 49,300 & 154,765 & 155,906 \\
$2-3$ & 421,606 & $1,002,141$ & 40,186 & 108,988 & 90,829 \\
\hline
\end{tabular}

$$
\begin{aligned}
\operatorname{clog} \log [h(t)]= & \log (-\log [1-h(t)])=\left(\alpha_{0}+\alpha_{1} T_{1}+\alpha_{2} T_{2}+\ldots \alpha_{10} T_{10}\right) \\
& +\left(\beta_{1} X_{1}+\beta_{2} X_{2}+\ldots \beta_{k} X_{k}\right)
\end{aligned}
$$

$$
h(t)=1-\exp \left[-\exp \left(\alpha_{0}+\alpha_{1} T_{1}+\alpha_{2} T_{2}+\ldots \alpha_{10} T_{10}\right)+\left(\beta_{1} X_{1}+\beta_{2} X_{2}+\ldots \beta_{k} X_{k}\right)\right]
$$

Equation (1) shows the cloglog transformed population hazard cloglog $[h(t)]$, modelled as a linear combination of predictor values, in which $T_{1}$ to $T_{10}$ are ten duration dummy variables, reflecting birth intervals; $X_{1}$ to $X_{k}$ are selected covariates; $\alpha_{1}$ to $\alpha_{10}$ and $\beta_{1}$ to $\beta_{10}$ are the coefficients and $\alpha_{0}$ is the intercept. With the estimated parameters, the predicted model-based discrete time hazard or conditional probability functions can easily be calculated using Eq. (2).

The CLL model is estimated by maximum likelihood, yielding estimates of both coefficients and baseline hazard function (Allison, 1982; Box-Steffensmeier \& Jones, 2004; Singer \& Willett, 2003). An anti-logged coefficient from the model with a clog-log link is the hazard ratio. The coefficients of predictor variables in the CLL model have the same interpretation as in the continuous-time Cox proportional 
hazards model. One-unit increase in a predictor variable multiplies the hazard by $\exp \left(\beta_{i}\right)$, where $\beta_{i}$ is the coefficient of the predictor variable and $\exp \left(\beta_{i}\right)$ is the hazard ratio or relative risk. Baseline hazard function captures duration effects, fitted as a step function with 10 time dummies because the birth interval was truncated at the 10th year. The reason for the truncation is due to the fact that the majority of married Chinese women space the successive births within 10 years. In the Eq. (1), the part $\left(\alpha_{0}+\alpha_{1} T_{1}+\alpha_{2} T_{2}+\ldots \alpha_{10} T_{10}\right)$ model the shape of the baseline hazard function, which is the population hazard function when all predictors $X_{1}$ to $X_{k}$ are set to 0 .

The advantages of applying the CLL model to analyze parity progression were described in a previous paper (Retherford et al., 2010). First, the model can easily handle both left censoring and right censoring, thereby enabling the application of the model to period data. Second, when a complementary log-log (cloglog) link is used instead of a logit link, the parameter estimates from the model can be directly interpreted as the ratios of continuous time hazard rates after anti-logging them. Third, in contrast to Cox regression, the CLL model provides an estimate of the shape of the baseline hazard function.

Separate CLL models were fitted to data from 1982, 1988, 1997, 2001 or 2006 surveys with the risks to second or third birth transition as the outcome event. The preliminary analysis shows some of the main effects to be similar, allowing the models to be combined. A multivariate life table is constructed after the CLL model is fitted, from which the parity progression ratios were derived (Retherford et al., 2010). The CLL modelling was carried out using the StataSE12 package (StataCorp., 2011). STATA uses the first category of dummy codes predictor variables as a default for the reference category. The birth interval is normally greater than one and the incidence of having the next birth in year 1 is very low. As a result, we may obtain high hazard ratios if we use year 1 as the reference category and therefore we chose year 10 as the reference category.

Explanatory variables The main explanatory variable is FPP. The policies change over time vary according to certain criteria, e.g. rural/urban (Hukou) and geographic location. Most existing measures of China's FPP have been constructed at the national level without accounting for regional nuances or changes in the policy over time. Results may not be reliable if incomplete, endogenous, or homogeneous measures of FPP are used. In this study, we integrate the policy variations more thoroughly and systematically, taking into account of heterogeneity and exogenous effects by using cross-sectional data from five consecutive of the China Population and Family Planning Surveys, which cover the whole period of FPP in question. We measure FPP as a time varying variable, reflecting on both changes in policy over time as well as distinguishing differential policies implemented after 1985 in urban and rural areas across different provinces. The exposure status to a particular policy was measured by each of the observation. Observations exposed to no FPP before year 1972 were coded '0'; those exposed to the 'later, longer, fewer FPP' (1973-1978) coded ' 1 '; those exposed to the 'nationwide one child FPP' (1979-1984) coded ' 2 '; and those exposed to the 'differentiated one child FPP' that was in place for urban Hukou residents nationwide and rural Hukou residents in 5 provinces after year 1985 were coded ' 3 '; those exposed to the 'one and half children FPP' in place for rural Hukou residents in 19 provinces after year 1985 to 2006 
coded '4'; and those exposed to 'two and more children FPP' for rural Hukou residents in operation in 5 provinces after 1985 were coded ' 5 '.

The educational attainment of the respondents was measured using three categories: primary education and below, lower secondary education and upper secondary and above education. In addition, we considered a set of relevant demographic and socioeconomic variables available uniformly across different surveys, including age at the previous parity, rural/urban residence, ethnicity, sex composition of children, provincial level contraceptive prevalence and household income. The provincial contraceptive prevalence rates were derived from individual survey data conducted in 1982, 1988, 1992, 1997, 2001 and 2006 and averaged within each province. The definition and coding of the variables is presented in the Appendix (Table 7). The number of woman-years in each category for the covariates is presented in Appendix Table 8.

\section{Results}

Sample characteristics First, we describe the socioeconomic characteristics of the study sample (Table 3). Over the study period, there has been an increase in the proportion of both urban residents and the average household annual income in rural and urban areas. The percentage of women with higher education had also increased over time. However, about $34 \%$ of women were in the lower education category in 2006. There was also a cohort effect, clearly reflected in the gradual decrease of the percentage with low education amongst younger cohorts. The consistency in the education levels across time for the same cohort indicates the reliability of this measurement. For instance, the cohort reflected in different age groups in each

Table 3 Percentage distribution of women aged $15-49$ by selected socioeconomic characteristics, various surveys

\begin{tabular}{|c|c|c|c|c|c|}
\hline \multirow{2}{*}{$\begin{array}{l}\text { Selected } \\
\text { characteristics }\end{array}$} & \multicolumn{5}{|l|}{ Surveys } \\
\hline & 1982 & 1988 & 1997 & 2001 & 2006 \\
\hline \multicolumn{6}{|l|}{ Residence } \\
\hline Urban & 16.9 & 24.5 & 23.4 & 25.5 & 34.3 \\
\hline Rural & 83.1 & 75.5 & 76.6 & 74.5 & 65.7 \\
\hline \multicolumn{6}{|l|}{ Ethnicity } \\
\hline Han & 93.3 & 89.5 & 90.9 & 90.6 & 89.1 \\
\hline Non-Han & 6.7 & 10.5 & 9.1 & 9.4 & 10.9 \\
\hline \multicolumn{6}{|l|}{ Education } \\
\hline Primary school \& below & 67.7 & 57.9 & 51.2 & 45.2 & 33.7 \\
\hline Lower secondary school & 22.2 & 28.2 & 32.2 & 36.1 & 41.6 \\
\hline Upper secondary and above & 10.1 & 13.9 & 16.6 & 18.8 & 24.7 \\
\hline \multicolumn{6}{|c|}{ Average household income (Yuan) } \\
\hline Urban & 535 & 1,180 & 5,160 & 6,860 & 11,760 \\
\hline Rural & 270 & 545 & 2,090 & 1,366 & 3,587 \\
\hline Number of women & 251,513 & 568,526 & 15,178 & 39,508 & 33,257 \\
\hline
\end{tabular}




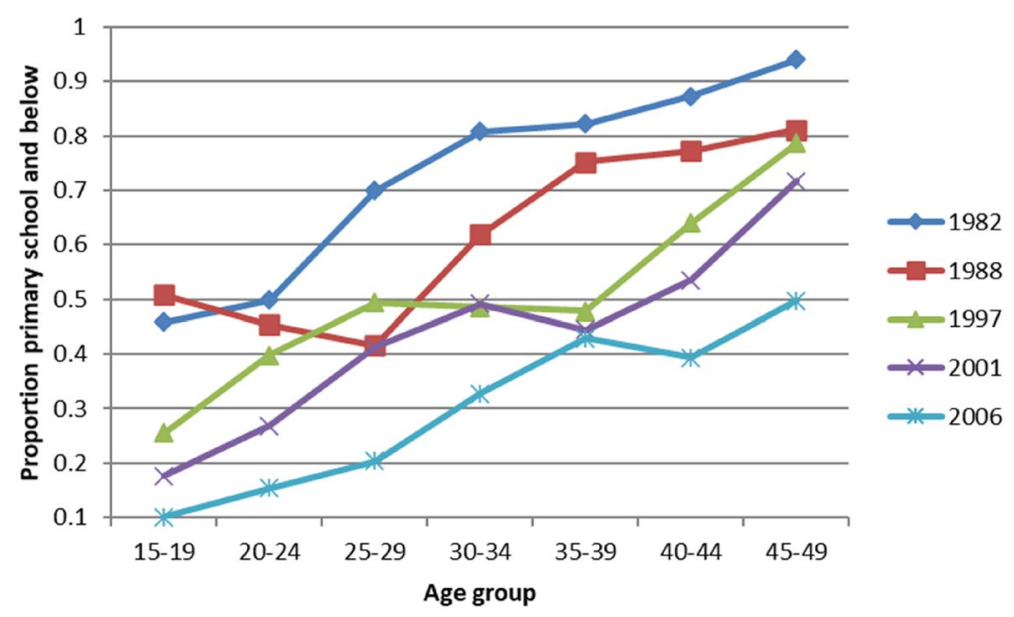

Fig. 2 Proportion of women aged $15-49$ by primary school and below education, various surveys

survey [45-49 (2006 survey), 40-44 (2001 survey), 35-39 (1997 survey), 25-29 (1988 survey) and 20-24 (1982 survey)], had similar education levels (Fig. 2).

Descriptive findings The probability of surviving (not progressing to parity 2-3) beyond 10 years by different FPP and education among women aged 15-49 years with parity one or two is shown in Fig. 3. The curves are estimated using the Kaplan-Meier survivor function. Women regulated under the 'differentiated one child FPP' had the highest survivorship, while those with 'no FPP' experienced the lowest survival. In between is the probability of surviving for women regulated under the 'differentiated one and half child FPP', 'nationwide one child FPP', 'differentiated two children FPP' and the 'later longer fewer FPP'. These results are consistent with what we would expect both in terms of the period in which the policies were in operation, and also given the differentiated nature of FPP. The surviving sequence of progressing from parity $2-3$ among subgroup regulated by different family planning policy was similar to those progressing from parity $1-2$. However, the gap in survivor probabilities between subgroups was larger for parity 2-3 progression than parity 1-2 progression.

As Fig. 3 shows, for both parity $1-2$ and parity $2-3$ transitions, women with primary school education experienced the lowest survivorship, which means they were most likely to progress to parity two or three, followed by those with lower secondary education. Women with upper secondary education were least likely to progress to parity two or to parity three. Log rank tests showed that the difference between FPP subgroups and education subgroups for both parity $1-2$ progression and parity 2-3 progression was significant.

Multivariate analysis Table 4 shows the results of multivariate complementary $\log -\log$ models for parity 1-2 transition. Model 1 presents the main effect of the different FPP regimes and education. A significant decrease in risk of transition to parity two was observed for the later FPPs. Compared with no policy regulation, there was no significant difference in the relative risk of parity transition from 1-2 among 


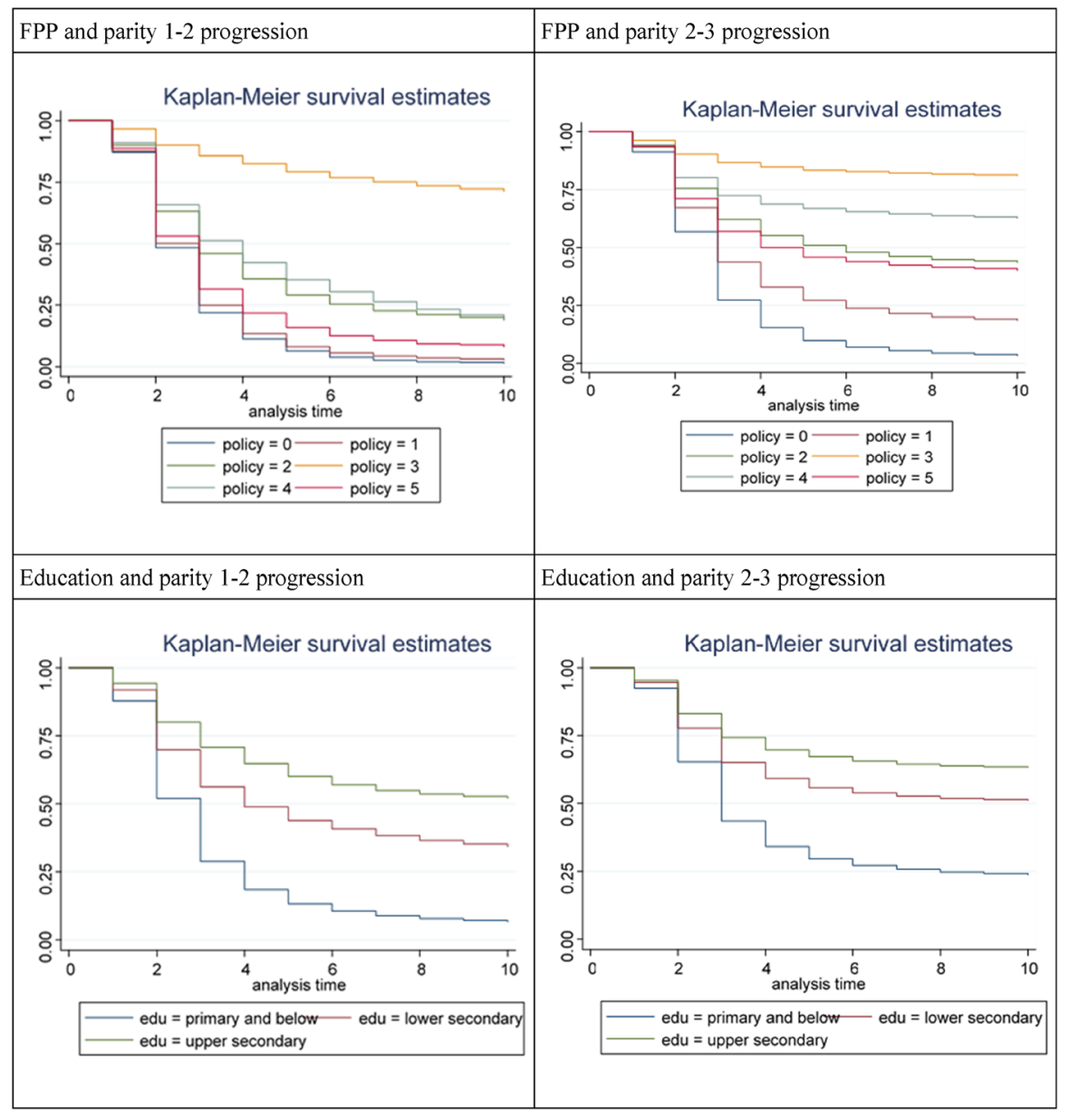

Fig. 3 Kaplan-Meier estimates of parity progression parity 1-2 and 2-3 by FPP and education (pooled data). Low eduprimary education and below, Medium edulower secondary education, High eduupper secondary and above education

women regulated under the 'later, longer, fewer FPP'. 'nationwide one child FPP', 'differentiated one child FPP', 'differentiated one and half children FPP' and 'differentiated two and more children FPP' were associated with 34\%, 76\%, 39\% and 26\% lower risk of a second birth respectively. Compared to women with lower education, higher educated women had a lower risk of parity progression. In contrast to women with primary school and below, women with lower secondary, and upper secondary or above education were associated with $17 \%$ and $32 \%$ lower risk respectively of experiencing a second birth.

S.E. standard errors

Women with higher socio-economic status experienced lower risk of parity transition. Women living in urban areas and those with higher household income had lower risk of experiencing a second birth compared to their rural counterparts and 
Table 4 Estimated relative risk of parity 1-2 progression among women aged 15-49, controlling for selected characteristics, pooled data

\begin{tabular}{|c|c|c|c|c|c|c|}
\hline \multirow[t]{2}{*}{ Characteristics } & \multicolumn{3}{|c|}{ Model 1 without interaction } & \multicolumn{3}{|c|}{ Model 2 with interactions } \\
\hline & $\operatorname{Exp}(\beta)$ & S.E. & $\mathrm{P}>\mathrm{Z}$ & $\operatorname{Exp}(\beta)$ & S.E. & $\mathrm{P}>\mathrm{Z}$ \\
\hline \multicolumn{7}{|l|}{ Period } \\
\hline Year 1 & 0.75 & 0.02 & 0.000 & 0.76 & 0.02 & 0.000 \\
\hline Year 2 & 2.98 & 0.09 & 0.000 & 3.04 & 0.09 & 0.000 \\
\hline Year 3 & 3.49 & 0.10 & 0.000 & 3.55 & 0.10 & 0.000 \\
\hline Year 4 & 2.95 & 0.08 & 0.000 & 2.99 & 0.09 & 0.000 \\
\hline Year 5 & 2.58 & 0.08 & 0.000 & 2.62 & 0.08 & 0.000 \\
\hline Year 6 & 2.04 & 0.06 & 0.000 & 2.06 & 0.06 & 0.000 \\
\hline Year 7 & 1.72 & 0.05 & 0.000 & 1.74 & 0.05 & 0.000 \\
\hline Year 8 & 1.43 & 0.05 & 0.000 & 1.44 & 0.05 & 0.000 \\
\hline Year 9 & 1.16 & 0.04 & 0.000 & 1.16 & 0.04 & 0.000 \\
\hline \multicolumn{7}{|l|}{ Year 10 (ref) } \\
\hline \multicolumn{7}{|l|}{ Family planning policy (FPP) } \\
\hline Later, longer, fewer & 1.00 & 0.00 & 0.652 & 1.02 & 0.00 & 0.000 \\
\hline Nationwide one child & 0.66 & 0.00 & 0.000 & 0.77 & 0.00 & 0.000 \\
\hline Differentiate one child & 0.24 & 0.00 & 0.000 & 0.39 & 0.01 & 0.000 \\
\hline Differentiate one and half children & 0.61 & 0.00 & 0.000 & 0.63 & 0.00 & 0.000 \\
\hline Differentiate two and more children FPP & 0.74 & 0.01 & 0.000 & 0.77 & 0.01 & 0.000 \\
\hline \multicolumn{7}{|l|}{ No FPP (ref) } \\
\hline \multicolumn{7}{|l|}{ Ethnicity } \\
\hline Han & 1.01 & 0.01 & 0.084 & 1.01 & 0.01 & 0.079 \\
\hline \multicolumn{7}{|l|}{ Non-Han (ref) } \\
\hline \multicolumn{7}{|l|}{ Education } \\
\hline Lower secondary school & 0.83 & 0.00 & 0.000 & 1.23 & 0.01 & 0.000 \\
\hline Upper secondary and above & 0.68 & 0.01 & 0.000 & 1.18 & 0.02 & 0.000 \\
\hline \multicolumn{7}{|l|}{ Primary school (ref) } \\
\hline \multicolumn{7}{|l|}{ Residence } \\
\hline Rural & 1.28 & 0.01 & 0.000 & 1.30 & 0.01 & 0.000 \\
\hline \multicolumn{7}{|l|}{ Urban (ref) } \\
\hline Age at the previous parity & 0.97 & 0.00 & 0.000 & 0.97 & 0.00 & 0.000 \\
\hline \multicolumn{7}{|l|}{ Sex composition of children } \\
\hline At least one son & 0.85 & 0.00 & 0.000 & 0.84 & 0.00 & 0.000 \\
\hline \multicolumn{7}{|l|}{ Only daughter (ref) } \\
\hline Contraceptive prevalence & 1.00 & 0.00 & 0.000 & 1.00 & 0.00 & 0.000 \\
\hline Average household income & 0.95 & 0.00 & 0.000 & 0.96 & 0.00 & 0.000 \\
\hline \multicolumn{7}{|l|}{ Year of survey } \\
\hline 1988 & 1.10 & 0.00 & 0.000 & 1.09 & 0.00 & 0.000 \\
\hline 1997 & 1.14 & 0.01 & 0.000 & 1.13 & 0.01 & 0.000 \\
\hline 2001 & 1.11 & 0.01 & 0.000 & 1.08 & 0.01 & 0.000 \\
\hline 2006 & 1.27 & 0.01 & 0.000 & 1.23 & 0.01 & 0.000 \\
\hline 1982 (ref) & & & & & & \\
\hline
\end{tabular}


Table 4 (continued)

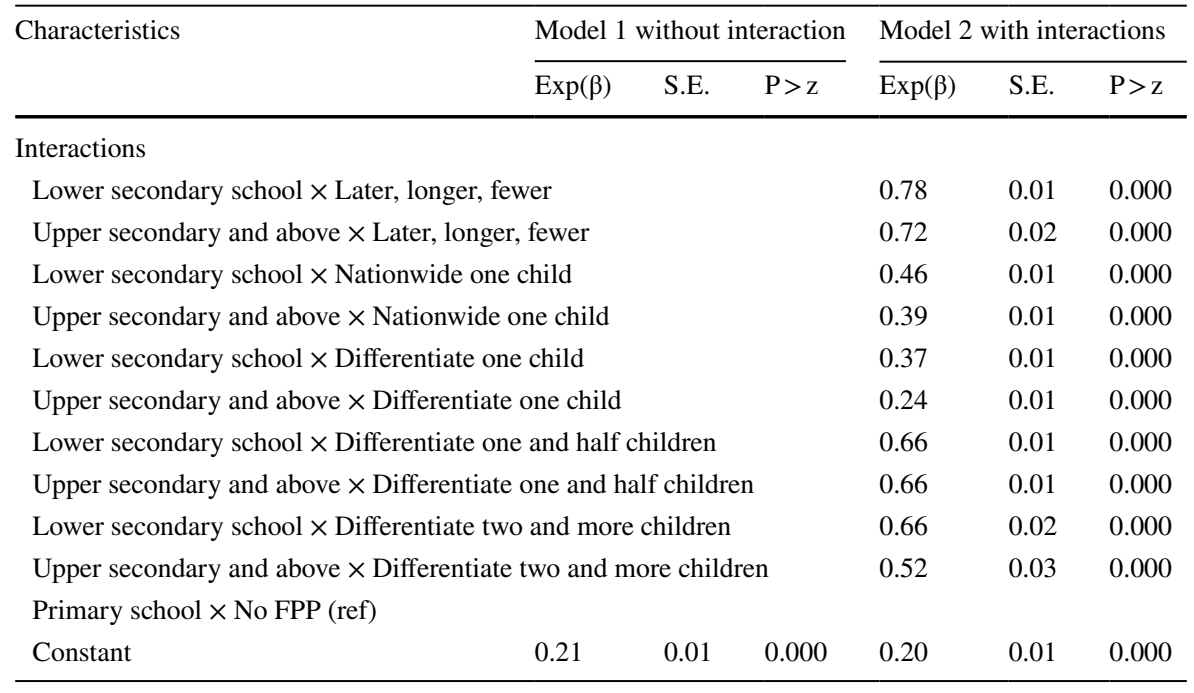

Pooled data from 1982, 1988, 1997, 2001 and 2006 surveys

those with lower household income. For the demographic characteristics, a higher age at first birth was associated with a lower transition risk. Han ethnicity women had slightly higher transition risk compared to Non-Han counterparts. Having a son was associated with $15 \%$ lower risk of the second birth compared to those having a daughter.

Table 5 shows the results of multivariate complementary log-log models for the transition from parity 2-3. Model 1 presents the main effect of FPP and education. The family planning policy regime had a bigger effect on the risk of the third birth compared to that of the second birth. Compared to no policy, exposure to the 'later, longer, fewer FPP', 'nationwide one child FPP', 'differentiated one child FPP', 'differentiated one and half children FPP' and 'differentiated two and more children FPP' were associated with $32 \%, 62 \%, 80 \%, 73 \%$ and $68 \%$ lower risk respectively of experiencing the third birth. Compared to lower education, higher educated women had a lower risk of parity progression. In contrast to women with primary school and below, having lower secondary and upper secondary or above education were associated with a $20 \%$ and $36 \%$ lower risk of a third birth respectively.

Living in urban areas or having a higher household income was associated with lower transition risk compare to their counterparts. The older the women when they had their second child, the lower the transition risk to third birth. Han ethnicity women had a lower transition risk compared to Non-Hans. Finally, having at least one son was associated with $36 \%$ lower risk of third birth than those having two daughters.

Model 2 in Tables 4 and 5 examines whether the effect of the FPP regime on parity transition was associated with the level of education. The interaction terms were significant which suggest that the impact of the FPP regime on parity transition was moderated by the level of women's education. To aid the interpretation 
Table 5 Estimated relative risk of parity 2-3 progression among women aged 15-49, controlling for selected characteristics, pooled data

\begin{tabular}{|c|c|c|c|c|c|c|}
\hline \multirow[t]{2}{*}{ Characteristics } & \multicolumn{3}{|c|}{ Model 1 without interaction } & \multicolumn{3}{|c|}{ Model 2 with interactions } \\
\hline & $\operatorname{Exp}(\beta)$ & S.E. & $\mathrm{P}>\mathrm{Z}$ & $\operatorname{Exp}(\beta)$ & S.E. & $\mathrm{P}>\mathrm{z}$ \\
\hline \multicolumn{7}{|l|}{ Period } \\
\hline Year 1 & 1.59 & 0.06 & 0.000 & 1.56 & 0.06 & 0.000 \\
\hline Year 2 & 7.26 & 0.29 & 0.000 & 7.14 & 0.28 & 0.000 \\
\hline Year 3 & 9.85 & 0.39 & 0.000 & 9.68 & 0.38 & 0.000 \\
\hline Year 4 & 7.04 & 0.28 & 0.000 & 6.92 & 0.27 & 0.000 \\
\hline Year 5 & 4.96 & 0.20 & 0.000 & 4.89 & 0.20 & 0.000 \\
\hline Year 6 & 3.50 & 0.14 & 0.000 & 3.46 & 0.14 & 0.000 \\
\hline Year 7 & 2.53 & 0.11 & 0.000 & 2.51 & 0.11 & 0.000 \\
\hline Year 8 & 1.83 & 0.08 & 0.000 & 1.82 & 0.08 & 0.000 \\
\hline Year 9 & 1.27 & 0.06 & 0.000 & 1.26 & 0.06 & 0.000 \\
\hline \multicolumn{7}{|l|}{ Year 10 (ref) } \\
\hline \multicolumn{7}{|l|}{ Family planning policy (FPP) } \\
\hline Later, longer, fewer & 0.68 & 0.00 & 0.000 & 0.70 & 0.00 & 0.000 \\
\hline Nationwide one child & 0.38 & 0.00 & 0.000 & 0.40 & 0.00 & 0.000 \\
\hline Differentiate one child & 0.20 & 0.00 & 0.000 & 0.21 & 0.01 & 0.000 \\
\hline Differentiate one and half children & 0.27 & 0.00 & 0.000 & 0.26 & 0.00 & 0.000 \\
\hline Differentiate two and more children FPP & 0.32 & 0.01 & 0.000 & 0.33 & 0.01 & 0.000 \\
\hline \multicolumn{7}{|l|}{ No FPP (ref) } \\
\hline \multicolumn{7}{|l|}{ Ethnicity } \\
\hline Han & 0.89 & 0.01 & 0.000 & 0.89 & 0.01 & 0.000 \\
\hline \multicolumn{7}{|l|}{ Non-Han (ref) } \\
\hline \multicolumn{7}{|l|}{ Education } \\
\hline Lower secondary school & 0.80 & 0.01 & 0.000 & 0.96 & 0.01 & 0.000 \\
\hline Upper secondary and above & 0.64 & 0.01 & 0.000 & 0.81 & 0.02 & 0.000 \\
\hline \multicolumn{7}{|l|}{ Primary school (ref) } \\
\hline \multicolumn{7}{|l|}{ Residence } \\
\hline Rural & 1.38 & 0.01 & 0.000 & 1.38 & 0.01 & 0.000 \\
\hline \multicolumn{7}{|l|}{ Urban (ref) } \\
\hline Age at the previous parity & 0.95 & 0.00 & 0.000 & 0.95 & 0.00 & 0.000 \\
\hline \multicolumn{7}{|l|}{ Sex composition of children } \\
\hline At least one son & 0.64 & 0.00 & 0.000 & 0.64 & 0.00 & 0.000 \\
\hline \multicolumn{7}{|l|}{ Only daughter (ref) } \\
\hline Contraceptive prevalence & 1.01 & 0.00 & 0.000 & 1.01 & 0.00 & 0.000 \\
\hline Average household income & 0.94 & 0.00 & 0.000 & 0.94 & 0.00 & 0.000 \\
\hline \multicolumn{7}{|l|}{ Year of survey } \\
\hline 1988 & 1.09 & 0.00 & 0.000 & 1.08 & 0.00 & 0.000 \\
\hline 1997 & 1.01 & 0.02 & 0.664 & 1.00 & 0.02 & 0.942 \\
\hline 2001 & 1.04 & 0.02 & 0.006 & 1.03 & 0.02 & 0.029 \\
\hline 2006 & 1.17 & 0.02 & 0.000 & 1.16 & 0.02 & 0.000 \\
\hline 1982 (ref) & & & & & & \\
\hline
\end{tabular}


Table 5 (continued)

\begin{tabular}{|c|c|c|c|c|c|c|}
\hline \multirow[t]{2}{*}{ Characteristics } & \multicolumn{3}{|c|}{ Model 1 without interaction } & \multicolumn{3}{|c|}{ Model 2 with interactions } \\
\hline & $\operatorname{Exp}(\beta)$ & S.E. & $\mathrm{P}>\mathrm{Z}$ & $\operatorname{Exp}(\beta)$ & S.E. & $\mathrm{P}>\mathrm{Z}$ \\
\hline \multicolumn{7}{|l|}{ Interactions } \\
\hline \multicolumn{4}{|c|}{ Lower secondary school $\times$ Later, longer, fewer } & 0.81 & 0.01 & 0.000 \\
\hline \multicolumn{4}{|c|}{ Upper secondary and above $\times$ Later, longer, fewer } & 0.63 & 0.02 & 0.000 \\
\hline \multicolumn{4}{|c|}{ Lower secondary school $\times$ Nationwide one child } & 0.62 & 0.01 & 0.000 \\
\hline \multicolumn{4}{|c|}{ Upper secondary and above $\times$ Nationwide one child } & 0.55 & 0.02 & 0.000 \\
\hline \multicolumn{4}{|c|}{ Lower secondary school $\times$ Differentiate one child } & 0.79 & 0.04 & 0.000 \\
\hline \multicolumn{4}{|c|}{ Upper secondary and above $\times$ Differentiate one child } & 0.77 & 0.06 & 0.000 \\
\hline \multicolumn{4}{|c|}{ Lower secondary school $\times$ Differentiate one and half children } & 0.94 & 0.02 & 0.009 \\
\hline \multicolumn{4}{|c|}{ Upper secondary and above $\times$ Differentiate one and half children } & 1.12 & 0.04 & 0.003 \\
\hline \multicolumn{4}{|c|}{ Lower secondary school $\times$ Differentiate two and more children } & 0.68 & 0.03 & 0.000 \\
\hline \multicolumn{4}{|c|}{ Upper secondary and above $\times$ Differentiate two and more children } & 0.87 & 0.07 & 0.098 \\
\hline \multicolumn{7}{|c|}{ Primary school $\times$ No FPP $($ ref $)$} \\
\hline Constant & 0.10 & 0.01 & 0.000 & 0.10 & 0.01 & 0.000 \\
\hline
\end{tabular}

Pooled data from 1982, 1988, 1997, 2001 and 2006 surveys.

S.E. standard errors

of the interaction between FP policy and education, we set all variables in the model to their mean value and estimated the probabilities for all combinations of education and FPP regime. Estimated parity progression ratios for every combination of education and FPP are presented in Table 6 and Fig. 4. The three levels of education are shown as three different lines and the six types of FPP regime are presented on the x-axis of the graph, with the differentiated policies (policy 3, policy 4, and policy 5) from 1985 presented separately. From the graphs, it is clear that the effect of the FPP regime varied accordingly to the level of education.

The plot shows that under the same FPP, women with higher education experienced a lower parity progression for both parity 1-2 and parity 2-3; and high educated women were more likely to comply with the policy (Fig. 4). For Parity 1-2, under no FPP regime, all three education groups had very high rates of progression. When the 'later, longer, fewer FPP' (policy 1) was introduced, the parity progression ratio to second child started to decline among high and medium educated women; when even more strict 'nationwide one child FPP' (policy 2) was introduced, the parity progression ratios to second child of high educated women declined more than those of low educated women.

In the strictest 'differentiated one child FPP' regime (policy 3), for all women, irrespective of their education levels, the parity progression declined. The educational differentials were small in the no FPP (policy 0), 'later, longer, fewer FPP' and 'differentiated one and half children FPP' regime (policy 4). In contrast, the educational differentials were large in the 'nationwide one child FPP', 'differentiated one child FPP' and 'differentiated two and more children FPP' regimes (policy 5). Interestingly, there was a potential 'bounce back' effect between policy 2 and 


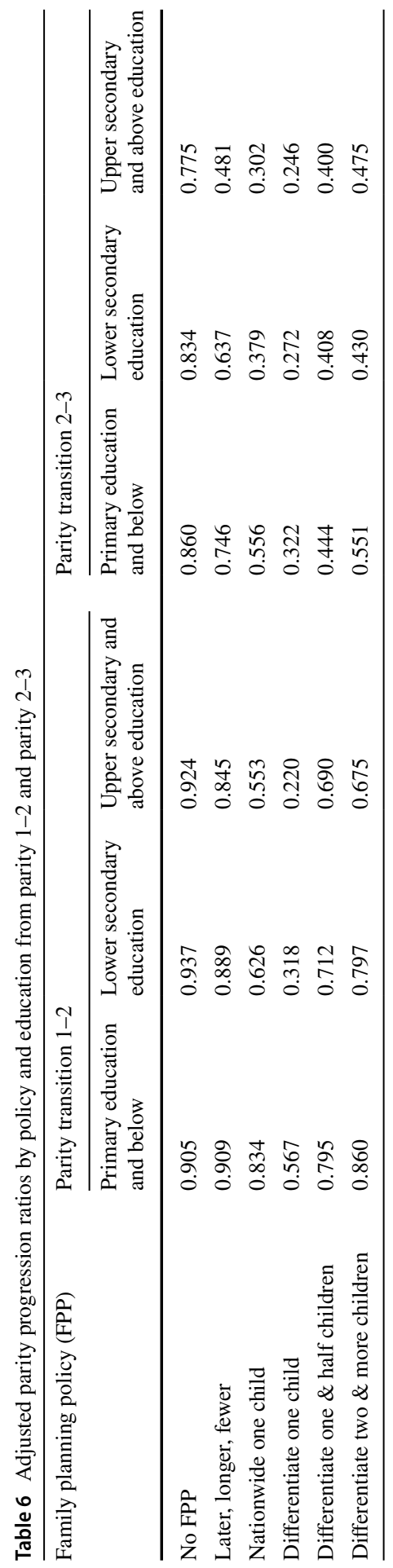




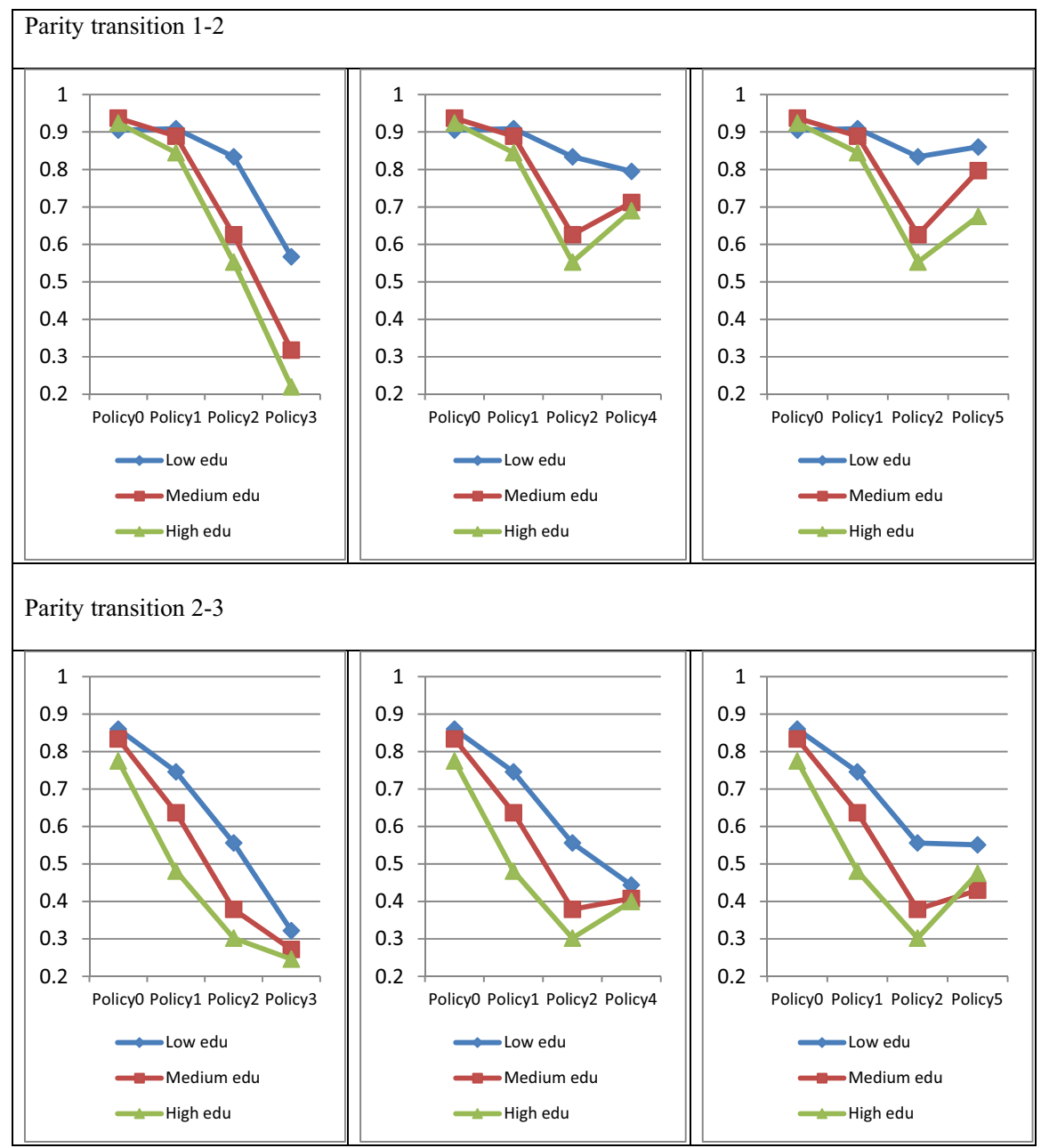

Note: Low edu= primary education and below; Medium edu= lower secondary education, High edu= upper secondary and above education.

Fig. 4 Adjusted parity progression ratios by policy and education

policies 4/5-indicating that in circumstances where the strict one child policy was relaxed, a higher proportion of educated women actually went on to a second birth - this suggests evidence to support the argument that there was a likely baby boom.

For Parity 2-3, under all policy regimes, women with primary education and below were the most likely to have a third birth, followed by those with lower secondary education and upper secondary and above education. The only exception being amongst those women exposed to the "differentiated two and more children FPP' regime, where high educated women had slightly higher parity progression to a third birth when compared to those with average or medium levels of education. From no FPP to 'later, longer, fewer FPP', the parity progression to third birth 
among all education level declined, with the pace of decrease being fastest among high educated women, followed by medium educated and low educated. From 'later, longer, fewer FPP' to 'nationwide one child FPP', parity progression ratios continued to drop almost in parallel across three education levels. The educational differentials narrowed as China moved from the 'nationwide one child FPP' to differentiated three types of FPP. The educational differentials were small in no FPP regime, and then widened during the 'later, longer, fewer FPP' and 'nationwide one child FPP' regimes, and then converged again during the differentiated three types of FPP.

When women had a choice to have a second or third child during a period with no FPP regime and in 'differentiated two and more children FPP', high educated women opted to remain with fewer children. For instance, parity progression ratio of parity 2-3 was lower for high educated women than that for low and medium educated women during no FPP regime; and parity progression ratio of parity 1-2 and parity2-3 was negatively associated with education during 'differentiated two and more children FPP'. It should be noted that the proportion of women in the high and medium education categories who were exposed to the relatively relaxed FPP regime was small. Education distribution by different FPP (see Appendix Table 9 and 10) shows that for parity 1-2, less than half of well educated women in the one and half children FPP and less than one third in the two children FPP had a second birth, while those for parity $2-3$, less than one third in the one and half children FPP and less than one fourth in the two children FPP had a third birth.

\section{Discussion}

The foregoing analyses confirmed our hypothesis that family planning policies (FPP) implemented over time had differential influence on educational groups in reducing the risk to second and third birth transition. The rates of progression to second and third births tend to be lower after the introduction of rigid FPP, and more importantly, the policy impact persisted even after adjusting for demographic and socioeconomic factors. The increase in women's education overall had a depressing effect on transition to higher parities, and family planning policies implemented overtime have had differential effects on women across different educational groups. The findings show that both family planning policies and women's education have been instrumental in shaping reproductive behavior in China.

Social institutions, population policies and family planning programs may influence fertility through changing internalized values concerning family, marriage and fertility (Bongaarts \& Sinding, 2011; Demeny, 2003; Entwisle \& Mason, 1985). FPP in China are confined to programmatic interventions aimed at increasing the availability of contraceptive services, and through massive Information, Education and Communication (IEC) campaigns the government was able to convince people of the potential value of low fertility for individual, family and the state welfare. The government complemented such efforts within a legislation frame, exerting administrative pressure or the establishment of outright sanctions for those unwilling to cooperate (Greenhalgh, 1986; Gu \& Li, 2010; Gu et al., 2007). 
We found a negative effect of women's education on parity transition. A possible underlying explanation is the increased opportunity costs associated with caring for children as the level of education increases. As women with high levels of education gain required skill sets useful in the marketplace, they tend to command a higher wage, thereby increasing the value of their time. Education also reduces the incentive to use fertility as a mechanism to increase family production and income (Basu, 2002; Caldwell, 1980, 2005; Cleland \& Wilson, 1987; Eloundou-Enyegue, 1999). Education has improved significantly over recent decades in China. Based on census figures, the illiteracy rates dropped from $33.6 \%$ in 1964 to $15.9 \%$ in 1990 and $6.7 \%$ in 2000. Between 1990 and 2000, the number of educated people per 100,000 increased dramatically across China. For example, the proportion of the population educated to primary level increased to $45.5 \%$, that of high school increased to $38.7 \%$, college and those educated to above college level increased by 1.5 times (Cai et al., 2001). The number of people in with tertiary education has soared from 8930 per 100,000 people in 2010 to 15,467 per 100,000 people in 2020, making China the largest and the fastest-growing population with tertiary education globally (Chen, 2021). If education has a negative association with fertility, increasing the level of women's education can potentially accelerate fertility decline. Our result is in agreement with other studies (Foster \& Roy, 1997; Martin, 1995).

In addition, our findings demonstrate that higher educated women are more likely to be the early adopters of the family planning policy, followed by their lower educated counterparts. There are a number of reasons to believe that education is positively associated with policy compliance. First, higher educated Chinese women are more likely to be employed in the public sector and they may face stricter sanctions if they resist the FPP. Second, education may directly affect the financial or psychic rewards from fertility behaviour itself. Finally, schooling may increase one's patience or risk aversion (Lance \& Enrico, 2004). On balance, we expect that most of these channels will lead to a negative relationship between education and compliance with a strict FPP. Moreover, diffusion of a small family size norms and knowledge of birth control information and services are likely to emerge among an elite group with higher levels of education, subsequently to be diffused across different social strata (Bras, 2014; Casterline, 2001; Cleland, 2001, 2002; Diamond et al., 1999). Government endorsement of family planning can have a legitimizing effect that can substantially reduce normative barriers against birth control (Freedman \& Berelson, 1978; Gertler \& Molyneaux, 1994). Diffusion then proceeds rapidly when purposive, organized programs include not only FPPs but also legislation and incentives for limiting family size — as has been the case in China.

Why have highly educated women responded with such alacrity to the relaxation of the policy? The possible explanation is that the majority of Chinese women's fertility desire was higher than the policy requirements in the 1980s (Zheng, 2004), so when policy was relaxed, high and medium educated women were likely to fulfil their fertility desire and at the same time adhere to the policy. While for the lower educated women, during the previous policy regime "nationwide one child FPP', more than 80 percent already had two children, which was not compliant with the policy. The parity progression ratio further declined from 0.834 ('nationwide 
one child FPP') to 0.795 ('differentiated one and half children FPP'), reflecting the fact that, with the provincial level fertility regulation in place in 1980s and family planning responsible system introduced in early 1990s, the implementation of FPP became more stricter than before.

China had recently announced in May 2021 that it would allow couples to have up to three children. The three-child policy is likely to produce marked effects on the rising number of third births in the short term because more reproductive-aged women across the country are now eligible to choose to have three children. Although in urban areas, the cost of raising children in cities has deterred many Chinese couples, in rural areas, it remains the societal norm to get married and have children. Nevertheless, it might be less likely to expect a sustained upsurge in births after the relaxed policy. The impact in terms of any increase in the absolute size of the population or a possible reversal of population ageing would be trivial (Padmadas, 2017). The fertility desire of Chinese women has become much lower than that in the 1980s. The national survey in 2013 and 2017 found that on average, Chinese women's ideal family size was 1.93 and 1.96 respectively, lower than the replacement level; and those with higher education expressed desire for even lower fertility (Zhuang et al., 2014, 2020). Moreover, the study shows that demographic factors, including the size of reproductive-age women and their age structure and the proportion of married and marital fertility, have been depressing birth numbers in recent years (Chen, 2021).

The initial aims of FPP in China were to enhance economic development to improve social and individual welfare. Policies of one kind or another have now been in force for more than 30 years. The Chinese approach to family planning has been criticized from both international and internal community for its human rights violations ever since the introduction of the authoritarian one child policy in 1979 (Greenhalgh, 2003). Nevertheless, under circumstances of low economic development and in a relatively short period of time, the country managed to achieve a remarkably low birth rate, and the exponential population growth has been effectively controlled. The decline in fertility has been accompanied by other demographic changes, such as accelerated population aging, distorted sex ratios, and changes to the Chinese family and kinship system (Cai, 2010; Cai et al., 2001). The FPP has been relaxed to a universal two-child FPP (Zeng \& Hesketh, 2016) and then a universal three-child FPP. Concerns have been voiced about an abrupt increase in births which in turn could have a dramatic effect on the allocation of resources, economic development and environmental carrying capacity. However, this study provides evidence that when women have choices to have another child, even within the number allowed under the FPP, higher educated women are more likely to have fewer children. The result is generally consistent with other studies. Recent research in Jiangsu province found that when women have the choice to have more children, many of them report reflecting on the balance between childbearing and family financial situation and quality of life, and choose not to do so (Mao \& Luo, 2013; Zheng et al., 2009). The pilot county of Yicheng where a two child policy has been the operation since 1980s provides further compelling empirical evidence that a baby boom might not appear as expected (Editorial Board of Population Research, 2007).

We conclude that FPP and women's education both played an important role in shaping fertility behaviour in China. Low fertility achieved in China is a joint 
outcome of both FPP and, as in other societies, increasing women's education-one of the key indicators of social and economic change in China. Had the strict FP policy been relaxed earlier, or not in place at all, then with the increase in women's education alongside other social and economic development, fertility levels may not be as high as assumed. The education-fertility relationship is relevant because the education level of a society can be directly influenced by government policy, and in turn gets entwined with development prospects. Increasing women's education and women's status is the most effective strategy to sustain fertility decline.

A major strength of our study is the coverage of the whole period of FPP, allowing a systematic evaluation of specify policy exposure more precisely at individual level and shedding light on the interaction of FP policy and education. By analyzing individual survey data, this study captures the heterogeneity of individual traits and the relationship between education-fertility links and policies. However, our study has also limitations. First, given the data restriction, we could not include the individual income and employment variables in the multivariate model. These two factors are important in Chinese context because violation of FPP implicates financial penalty and public job security. Secondly, we observe the dynamic effects of different FPP regimes on women's childbearing behavior in that specific period. In order to cover the full historical period, we pooled data from five separate surveys; the observations in each cross section do not refer to the same unit. The crucial question with pooled cross sectional data from different time periods is that the same model might not apply in each time period; changes in regulation could cause behaviors to be different; other factors that might cause coefficients in one period to differ from those in others (Bass \& Wittink, 1975). We use a general way of modelling the differences in intercept terms or slope coefficients between periods by applying survey dummies. We also modelled the period data separately by different surveys, and the results were consistent (data not shown separately). However, the model estimates could be biased because the time dummies might not have fully captured the contextual changes over the observation period. Finally, due to data restrictions, the present study could not fully investigate the social and cultural factors (Newman \& Hugo, 2006) which can be prominent in explaining the fertility transition across different geographies within China. Further research is needed to understand the magnitude of association between policy and social and cultural factors.

The role and influence of national fertility policy interventions and programs have been established in most regions in China. Future research could use data from updated surveys to further reveal the complex pathways of education and other institutional influence on the course of fertility outcomes. In particular, within the context of a universal two-child or three-child policy, more attention needs to be paid to understanding the mechanisms of how FPP and education might affect fertility through the demand and supply of children and related opportunity costs.

\section{Appendix}

See Tables 7, 8, 9 and 10. 


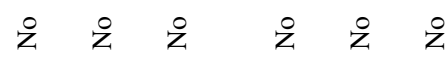

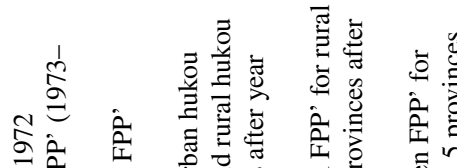

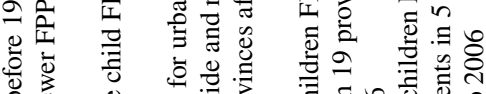

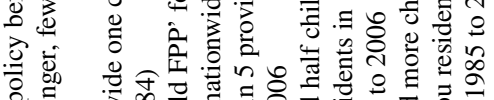

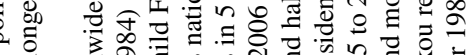

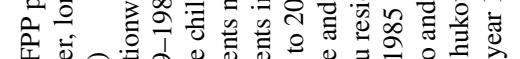

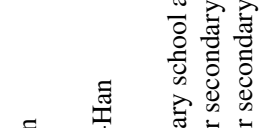

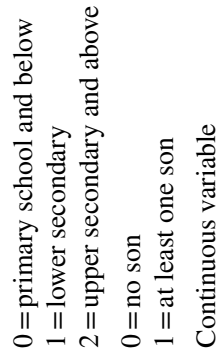

音

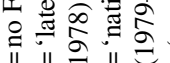

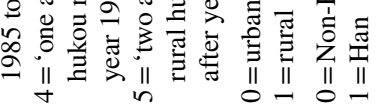
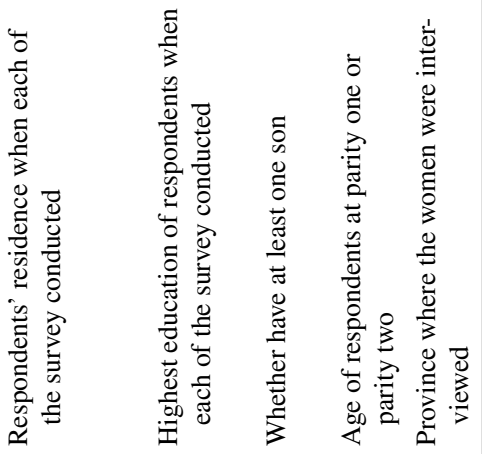

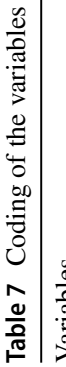

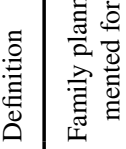
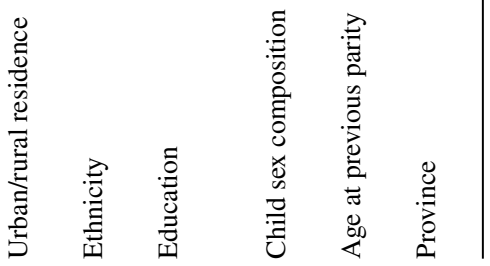


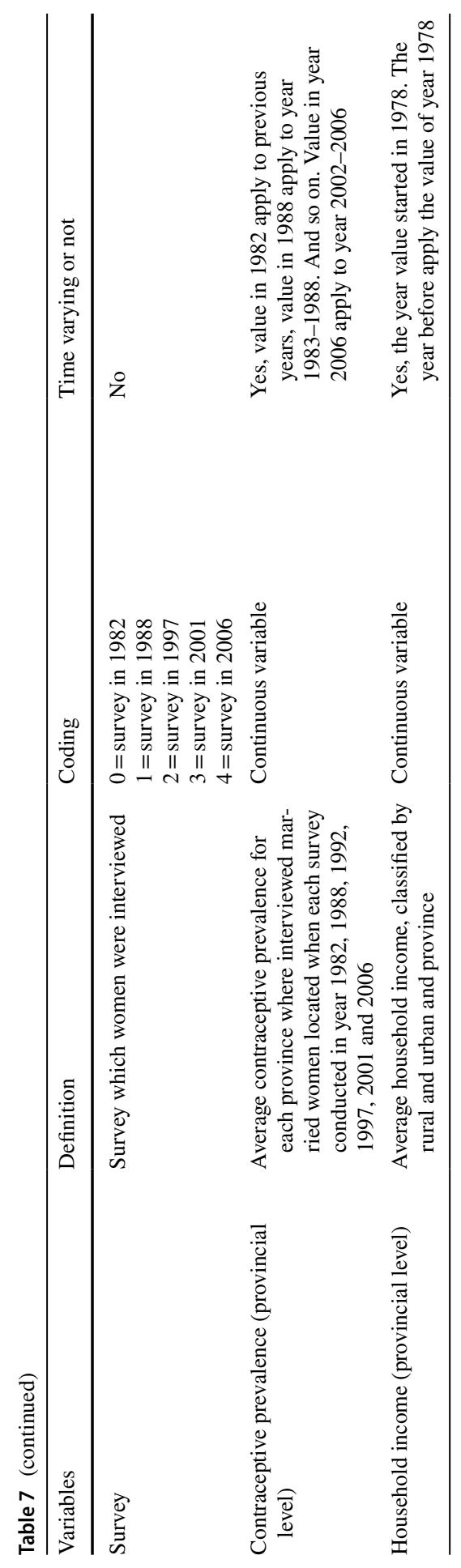


Table 8 Number of woman-years in each category for the covariates in the multivariate CLL models

\begin{tabular}{|c|c|c|c|c|}
\hline & \multicolumn{2}{|l|}{ Parity $1-2$} & \multicolumn{2}{|l|}{ Parity $2-3$} \\
\hline & Frequency & Percentage & Frequency & Percentage \\
\hline Year 1 & 592,540 & 31.09 & 416,407 & 25.03 \\
\hline Year 2 & 478,485 & 25.11 & 357,284 & 21.47 \\
\hline Year 3 & 288,764 & 15.15 & 245,179 & 14.74 \\
\hline Year 4 & 173,288 & 9.09 & 160,333 & 9.64 \\
\hline Year 5 & 116,835 & 6.13 & 121,342 & 7.29 \\
\hline Year 6 & 83,295 & 4.37 & 98,789 & 5.94 \\
\hline Year 7 & 60,904 & 3.20 & 82,317 & 4.95 \\
\hline Year 8 & 46,127 & 2.42 & 70,358 & 4.23 \\
\hline Year 9 & 36,420 & 1.91 & 60,589 & 3.64 \\
\hline Year 10 (ref) & 29,154 & 1.53 & 51,152 & 3.07 \\
\hline No FPP (ref) & 489,932 & 25.71 & 392,774 & 23.61 \\
\hline Later, longer, fewer FPP & 291,994 & 15.32 & 345,212 & 20.75 \\
\hline Nationwide one child FPP & 438,197 & 22.99 & 439,771 & 26.43 \\
\hline Differentiate one child FPP & 351,023 & 18.42 & 121,949 & 7.33 \\
\hline Differentiate one and half children FPP & 305,449 & 16.03 & 327,732 & 19.70 \\
\hline Differentiate two and more children FPP & 29,217 & 1.53 & 36,312 & 2.18 \\
\hline Non-Han ethnicity(ref) & 161,090 & 8.45 & 144,959 & 8.71 \\
\hline Han Ethnicity & $1,744,722$ & 91.55 & $1,518,791$ & 91.29 \\
\hline Primary school (ref) & $1,168,070$ & 61.29 & $1,259,783$ & 75.72 \\
\hline Lower secondary school & 475,819 & 24.97 & 290,461 & 17.46 \\
\hline Upper secondary and above & 261,923 & 13.74 & 113,506 & 6.82 \\
\hline Urban residence(ref) & 552,229 & 28.98 & 332,274 & 19.97 \\
\hline Rural residence & $1,353,583$ & 71.02 & $1,331,476$ & 80.03 \\
\hline \multicolumn{5}{|l|}{ Age at the previous parity } \\
\hline $15-19$ & 301,501 & 15.82 & 52,492 & 3.16 \\
\hline $20-29$ & $1,560,361$ & 81.87 & $1,467,534$ & 88.21 \\
\hline $30-49$ & 43,950 & 2.31 & 143,724 & 8.64 \\
\hline Only daughter (ref) & 881,677 & 46.26 & 793,849 & 47.71 \\
\hline At least one son & $1,024,135$ & 53.74 & 869,901 & 52.29 \\
\hline \multicolumn{5}{|l|}{ Contraceptive prevalence } \\
\hline $37.0-69.9$ & 413,726 & 21.71 & 399,397 & 24.01 \\
\hline $70.0-79.9$ & $1,108,464$ & 58.16 & $1,024,080$ & 61.55 \\
\hline $80.0-93.9$ & 383,622 & 20.13 & 240,273 & 14.44 \\
\hline \multicolumn{5}{|l|}{ Average household income } \\
\hline $1.00-2.99$ & 573,820 & 30.38 & 551,351 & 33.47 \\
\hline $3.00-5.99$ & 685,680 & 36.30 & 725,209 & 44.02 \\
\hline $6.00-207$ & 629,615 & 33.33 & 370,868 & 22.51 \\
\hline 1982 survey (ref) & 420,254 & 22.05 & 421,606 & 25.34 \\
\hline 1988 survey & $1,125,587$ & 59.06 & $1,002,141$ & 60.23 \\
\hline 1997 survey & 49,300 & 2.59 & 40,186 & 2.42 \\
\hline 2001 survey & 154,765 & 8.12 & 108,988 & 6.55 \\
\hline
\end{tabular}


Table 8 (continued)

\begin{tabular}{|c|c|c|c|c|}
\hline & \multicolumn{2}{|l|}{ Parity $1-2$} & \multicolumn{2}{|l|}{ Parity $2-3$} \\
\hline & Frequency & Percentage & Frequency & Percentage \\
\hline 2006 survey & 155,906 & 8.18 & 90,829 & 5.46 \\
\hline \multicolumn{5}{|l|}{30 provinces } \\
\hline Beijing & 58,477 & 3.07 & 36,134 & 2.17 \\
\hline Tianjin & 47,884 & 2.51 & 28,504 & 1.71 \\
\hline Hebei & 94,287 & 4.95 & 85,934 & 5.17 \\
\hline Shanxi & 58,209 & 3.05 & 58,255 & 3.50 \\
\hline Neimenggu & 52,257 & 2.74 & 47,305 & 2.84 \\
\hline Liaoning & 88,750 & 4.66 & 60,914 & 3.66 \\
\hline Jilin & 62,108 & 3.26 & 49,217 & 2.96 \\
\hline Heilongjiang & 71,888 & 3.77 & 58,101 & 3.49 \\
\hline Shanghai & 65,512 & 3.44 & 34,617 & 2.08 \\
\hline Jiangsu & 117,008 & 6.14 & 91,474 & 5.50 \\
\hline Zhejiang & 78,309 & 4.11 & 71,956 & 4.32 \\
\hline Anhui & 66,434 & 3.49 & 68,251 & 4.10 \\
\hline Fujian & 50,875 & 2.67 & 51,404 & 3.09 \\
\hline Jiangxi & 52,812 & 2.77 & 53,682 & 3.23 \\
\hline Shandong & 113,788 & 5.97 & 93,514 & 5.62 \\
\hline Henan & 94,481 & 4.96 & 88,824 & 5.34 \\
\hline Hubei & 79,649 & 4.18 & 74,232 & 4.46 \\
\hline Hunan & 76,667 & 4.02 & 77,608 & 4.66 \\
\hline Guangdong & 72,380 & 3.80 & 70,654 & 4.25 \\
\hline Guangxi & 49,493 & 2.60 & 49,080 & 2.95 \\
\hline Hainan & 22,033 & 1.16 & 21,392 & 1.29 \\
\hline Chongqing & 8,914 & 0.47 & 4,276 & 0.26 \\
\hline Sichuan & 123,415 & 6.48 & 99,989 & 6.01 \\
\hline Guizhou & 45,393 & 2.38 & 44,366 & 2.67 \\
\hline Yunnan & 56,191 & 2.95 & 55,035 & 3.31 \\
\hline Shaanxi & 62,257 & 3.27 & 61,180 & 3.68 \\
\hline Gansu & 49,499 & 2.60 & 48,263 & 2.90 \\
\hline Qinghai & 23,566 & 1.24 & 21,354 & 1.28 \\
\hline Ningxia & 22,579 & 1.18 & 22,116 & 1.33 \\
\hline Xinjiang & 40,697 & 2.14 & 36,119 & 2.17 \\
\hline
\end{tabular}




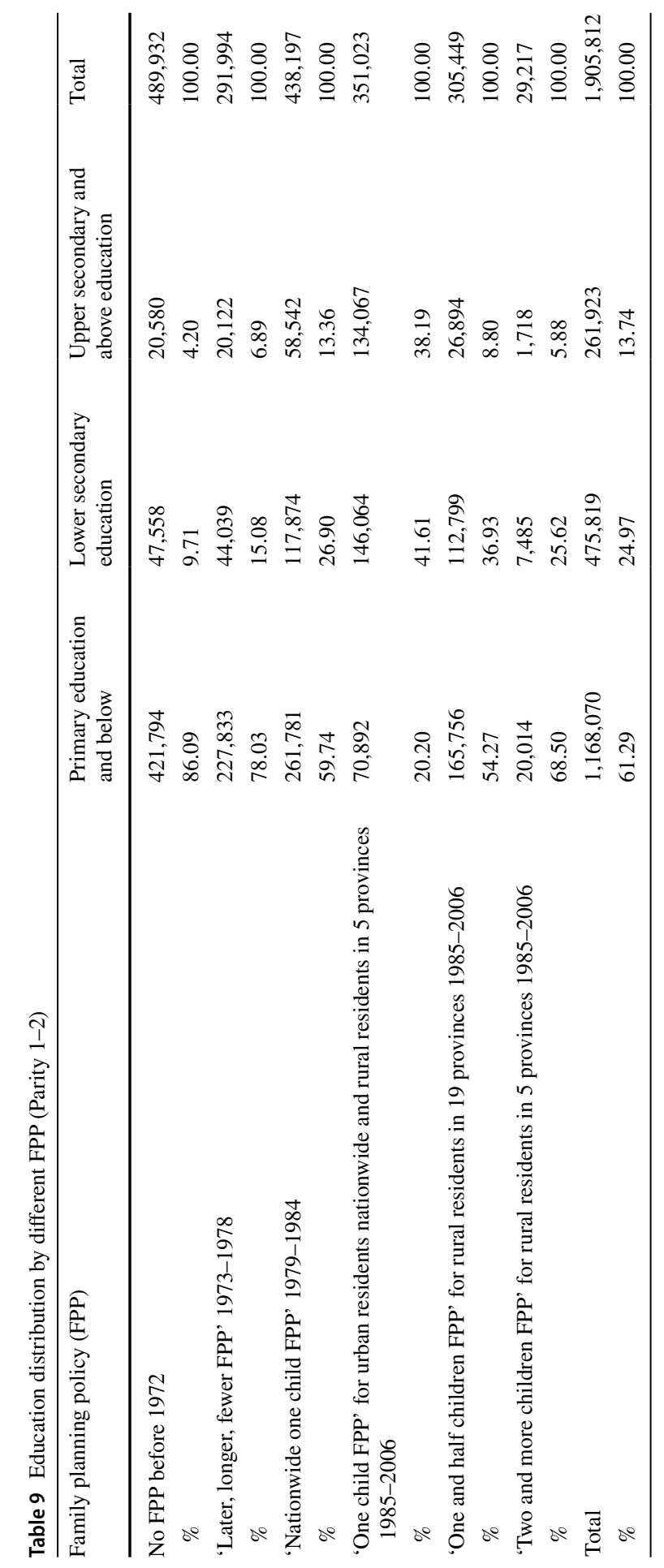




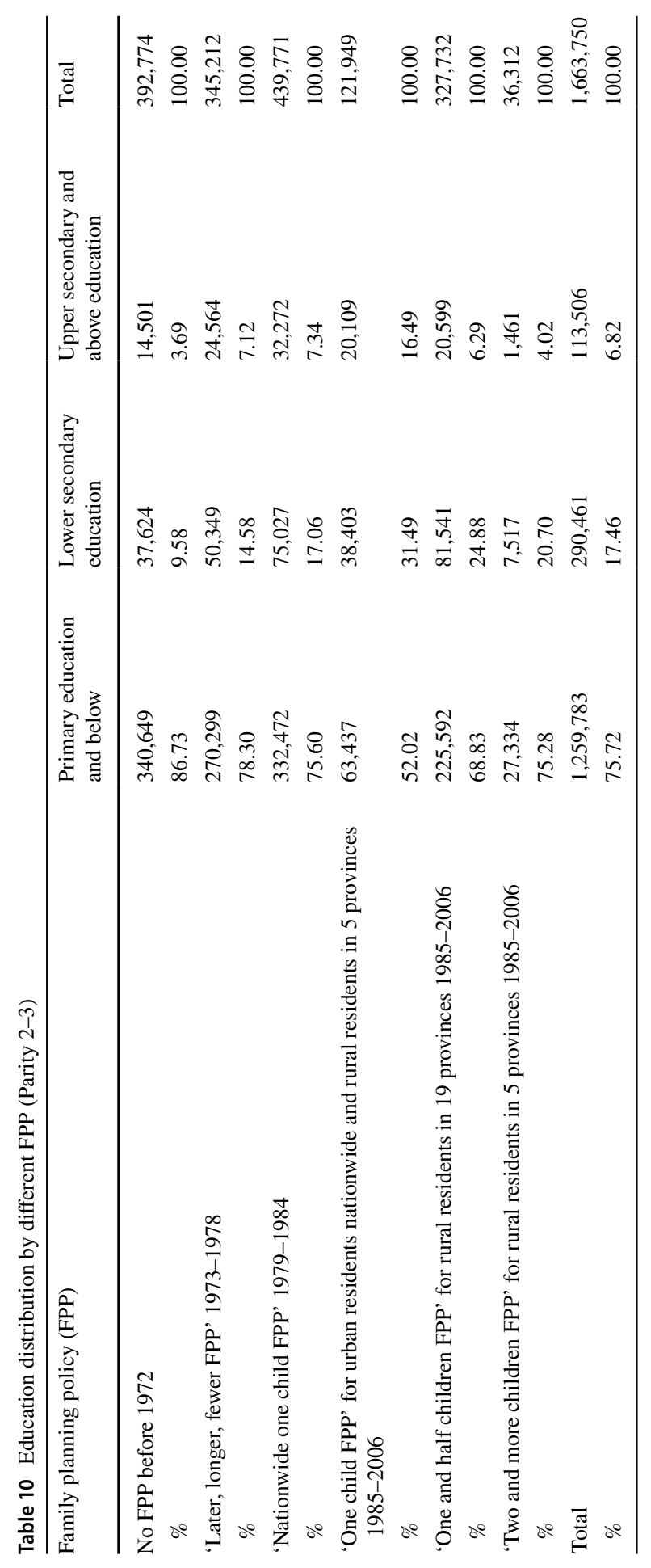


Acknowledgements The financial support for this research was provided by the UK Economic and Social Research Council (Reference: ES/J500161/1). We are grateful to Andrew Hinde, Dudley L. Poston Jr and Li Bohua for their constructive and thoughtful comments. We thank Robert Retherford and Hassan EiniZinab for their generosity in sharing the computer programs which facilitated the statistical modelling of parity progression-based measures of the total fertility rate.

\section{Declarations}

Conflict of interest The authors state that there is no conflict of interest.

Open Access This article is licensed under a Creative Commons Attribution 4.0 International License, which permits use, sharing, adaptation, distribution and reproduction in any medium or format, as long as you give appropriate credit to the original author(s) and the source, provide a link to the Creative Commons licence, and indicate if changes were made. The images or other third party material in this article are included in the article's Creative Commons licence, unless indicated otherwise in a credit line to the material. If material is not included in the article's Creative Commons licence and your intended use is not permitted by statutory regulation or exceeds the permitted use, you will need to obtain permission directly from the copyright holder. To view a copy of this licence, visit http://creativecommons.org/licen ses/by/4.0/.

\section{References}

Allison, P. D. (1982). Discrete-time methods for the analysis of event histories. Sociological Methodology, 13, 61-98. https://doi.org/10.2307/270718.

Attané, I. (2002) China's family planning policy: An overview of its past and future. Studies in Family Planning, 33(1), 103-113. http://www.jstor.org/stable/2696336. Accessed 7 Oct 2021.

Bass, F. M., \& Wittink, D. R. (1975). Pooling issues and methods in regression analysis with examples in marketing research. Journal of Marketing Research, 12(4), 414-425. https://doi.org/10.1177/00222 4377501200405.

Basu, A. M. (2002). Why does education lead to lower fertility? A critical review of some of the possibilities. World Development, 30(10), 1779-1790. https://doi.org/10.1016/S0305-750X(02)00072-4.

Behrman, J. A. (2015). Does schooling affect women's desired fertility? Evidence from Malawi, Uganda, and Ethiopia. Demography, 52, 787-809. https://doi.org/10.1007/s13524-015-0392-3.

Bongaarts, J. (1994). Population policy options in the developing world. Science, 263, 771-776. http:// www.jstor.org/stable/2882916. Accessed 7 Oct 2021.

Bongaarts, J. (2003). Completing the fertility transition in the developing world: The role of educational differences and fertility preferences. Population Studies, 57(3), 321-335. https://doi.org/10.1080/ 0032472032000137835 .

Bongaarts, J., \& Greenhalgh, S. (1985). An alternative to the one-child policy in China. Population and Development Review, 11(4), 585a-5617. https://doi.org/10.2307/1973456.

Bongaarts, J., \& Potter, R. G. (1983). Fertility, biology and behavior: An analysis of the proximate determinants. Academic Press.

Bongaarts, J., \& Sinding, S. (2011). Population policy in transition in the developing world. Science, 333, 574-575. https://doi.org/10.1126/science.1207558.

Box-Steffensmeier, J., \& Jones, B. S. (2004). Event history modeling. Cambridge University Press.

Bras, H. (2014). Structural and diffusion effects in the Dutch fertility transition, 1987-1940. Demographic Research, 30(5), 151-186. https://doi.org/10.4054/DemRes.2014.30.5.

Bulatao, R. A. (1998). The value of family planning programs in developing countries, Santa Monica, California: RAND Corporation, MR-978-WHFH/RF/UNFPA.

Cai, Y. (2010). China's below-replacement fertility: government policy or socioeconomic development? Population and Development Review, 36, 419-440. http://www.jstor.org/stable/25749195. Accessed 7 Oct 2021. 
Cai, F., Wang, Z. M., Wang, M. Y. (2001). Population and family planning policy: Implementation and impact. Working Paper Series No.14, Beijing: Chinese Academy of Social Sciences (in Chinese).

Caldwell, J.C. (1980). Mass education as a determinant of the timing of fertility decline. Population and Development Review, 6(2), 225-255. https://www.jstor.org/stable/1972729. Accessed 7 Oct 2021.

Caldwell, J.C. (2005). On net intergenerational wealth flows: An update. Population and Development Review, 31(4), 721-740. http://www.jstor.org/stable/3401523. Accessed 7 Oct 2021.

Casterline, J. B. (2001). Diffusion processes and fertility transition: Introduction. In J. B. Casterline (Ed.), Diffusion process and fertility transition: Selected perspectives (pp. 1-38). National Academy Press.

Chen, W. (2021). Declining number of births in China: A decomposition analysis. China Population and Development Studies, 5, 215-228. https://doi.org/10.1007/s42379-021-00094-6.

Chen, J., Retherford, R. D., Choe, M. K., Li, \& Hu, Y. (2009). Province-level variation in the achievement of below-replacement fertility in China. Asian Population Studies, 5, 309-327. https://doi.org/ 10.1080/17441730903351651.

Cleland, J. (2001). Potatoes and pills: An overview of innovation-diffusion contribution to explanations of fertility decline. In J. B. Casterline (Ed.), Diffusion process and fertility transition: Selected perspectives (pp. 39-65). National Academy Press.

Cleland, J. (2002). Education and future fertility trends, with reference to mid-transitional countries. In United Nations (ed.) Completing the fertility transition. Special Issue No. 48/49, United Nations Department of Economic and Social Affairs, 183-194.

Cleland, J., \& Rodriguez, G. (1988). The effect of parental education on marital fertility in developing countries. Population Studies, 42, 419-442. http://www.jstor.org/stable/2174405. Accessed 7 Oct 2021.

Cleland, J., \& Wilson, C. (1987). Demand theories of the fertility transition: An iconoclastic view. Population Studies, 41(1), 5-30. https://doi.org/10.1080/0032472031000142516.

Cochrane, S. H. (1979). Fertility and education: what do we really know? World Bank staff occasional papers; No. OCP26. Baltimore, MD: The Johns Hopkins University Press. http://documents.world bank.org/curated/en/1979/01/1558317/fertility-education-really-know. Accessed 11 May 2016.

Colleran, H., Jasienska, G., Nenko, I., Galbarczyk, A., \& Mace, R. (2014). Community-level education accelerates the cultural evolution of fertility decline. Proceedings of the Royal Society B, 281(1779), 20132732. https://doi.org/10.1098/rspb.2013.2732.

Demeny, P. (2003). Population policy: A concise summary. Working Paper No.173, New York: The Population Council.

Diamond, I., Newby, M., \& Varle, S. (1999). Female education and fertility: Examining the links. In J. B. Casterline, J. A. Johnson-Kuhn, \& J. G. Haaga (Eds.), Critical perspectives on schooling and fertility in the developing world, Bledsoe, C.H. National Academy Press.

Drèze, J., \& Murthi, M. (2001). Fertility, education, and development: Evidence from India. Population and Development Review, 27, 33-63. http://www.jstor.org/stable/2695154. Accessed 7 Oct 2021.

Editorial Board of Population Research. (2007). Practice and implication of two children policy. Population Research, 32(4), 33-49. (in Chinese).

Eloundou-Enyegue, P. (1999). Fertility and education: What do we now know? In J. B. Casterline, J. A. Johnson-Kuhn, \& J. G. Haaga (Eds.), Critical perspectives on schooling and fertility in the developing world, Bledsoe, C.H. National Academy Press.

Entwisle, B., \& Mason, W. M. (1985). Multilevel effects of socioeconomic development and family planning programs on children ever born. American Journal of Sociology, 91(3), 616-649. https://doi. org/10.1086/228316.

Feeney, G., \& Wang, F. (1993). Parity progression and birth intervals in China: The influence of policy in hastening fertility decline. Population and Development Review, 19(1), 61-101. https://doi.org/10. $2307 / 2938385$.

Feeney, G., \& Yu, J. (1987). Period parity progression measures of fertility in China, Population Studies, 41, 77-102. https://www.jstor.org/stable/2174327. Accessed 7 Oct 2021.

Feeney, G., \& Yuan, J. H. (1994). Below replacement fertility in China? A close look at recent evidence. Population Studies, 48(3), 381-394. https://doi.org/10.1080/0032472031000147926.

Foster, A., \& Roy, N. (1997). The dynamics of education and fertility: Evidence from a family planning experiment. University of Pennsylvania Mimeo.

Freedman, R., \& Berelson, B. (1978). The record of family planning programs. Studies in Family Planning, 7(1), 1-40.

Gertler, P., \& Molyneaux, J. (1994). How economic development and family planning combined to reduce fertility in Indonesia. Demography, 31, 33-64. 
Greenhalgh, S. (2003). Science, modernity, and the making of China's one-child policy. Population and Development Review, 29(2), 163-196. http://www.jstor.org/stable/3115224. Accessed 7 Oct 2021.

Greenhalgh, S. (1986). Shift in China's population policy, 1984-86: View from the central, provincial, and local levels. Population and Development Review, 12(3), 491-515. https://doi.org/10.2307/ 1973220.

Gu, B., Wang, F., Guo, Z. G., \& Zhang, E. L. (2007). China's local and national fertility policies at the end of the twentieth century, Population and Development Review, 33(1), 129-147. http://www. jstor.org/stable/25434587. Accessed 7 Oct 2021.

Gu, B., \& Li, J. X. (2010). The debate on China's population policy in the 21st Century. Social Sciences Academic Press. (in Chinese).

Hardee-Cleaveland, K., \& Banister, J. (1988). Fertility policy and implementation in China, 1986-1988. Population and Development Review, 14(2), 245-286. https://doi.org/10.2307/1973572.

Hesketh, T., Lu, L., \& Xing, Z. W. (2005). The effect of China's one-child family policy after 25 years. New England Journal of Medicine, 353(11), 1116-1171. https://doi.org/10.1056/NEJMhpr051833.

James, K. S., Skirbekk, V., \& Bavel, J. V. (2012). Education and the global fertility transition: Foreword. Vienna Yearbook of Population Research, 10, 1-8. http://www.jstor.org/stable/41940994. Accessed 7 Oct 2021.

Jeffrey, R., \& Basu, A. M. (1996). Girls' schooling, women's autonomy and fertility change in South Asia. Sage.

Jejeebhoy, S. J. (1995). Women's education, autonomy, and reproductive behaviour: Experience from Developing Countries. Clarendon Press.

Joshi, S., \& Schultz, T. P. (2013). Family planning and women's and children's health: Long-term consequences of an outreach program in Matlab, Bangladesh. Demography, 50(1), 149-180. https://doi.org/10.1007/s13524-012-0172-2.

Kravdal, Ø. (2002). Education and fertility in sub-Saharan Africa: Individual and community effects. Demography, 39(2), 233-250. https://doi.org/10.2307/3088337

Lance, L., \& Enrico, M. (2004). The effect of education on crime: Evidence from prison inmates, arrests and self-reports. American Economic Review, 94(1), 155-189. https://doi.org/10.1257/ 000282804322970751.

Lavely, W., Zhenyu, X., Li, B. \& Freedman, R. (1990). The rise in female education in China: National and regional patterns. The China Quarterly, 121, 61-93. http://www.jstor.org/stable/ 654063. Accessed 7 Oct 2021.

Liu, J. (1994). Education in post-Mao China. Comparative Education Review, 38(4), 550-553. https:// doi.org/10.1086/447277

Liu, Y., Hsiao, W. C. L., Li, Q., Liu, \& Ren, M. (1995). Transformation of China's rural health care financing. Social Science \& Medicine, 41(8), 1085-1093. https://doi.org/10.1016/0277-9536(95) 00428-a.

Mao, Z. Y., \& Luo, H. (2013). Difference between fertility intention and fertility behaviour for women subject to the two -children policy: An empirical study based on the theory of planned behaviour. Population Research, 37(1), 84-93. (in Chinese).

Martin, T. C. (1995). Women's education and fertility: Results from 26 demographic and health surveys. Studies in Family Planning, 26(4), 187-202.

Martin, T. C., \& Juárez, F. (1995). The impact of women's education on fertility in Latin America: Searching for explanations. International Family Planning Perspectives, 21, 52-57. 80.

Mason, K. O. (1987). The impact of women's social position on fertility in developing countries. Sociological Forum, 2, 718-745. http://www.jstor.org/stable/684300. Accessed 7 Oct 2021.

Merli, G. M., \& Smith, H. L. (2002). Has the Chinese birth planning program been successful in changing fertility preferences? Evidence from linked records in three data sources in four counties of Northern China. Demography, 39(3), 557-572. https://doi.org/10.1353/dem.2002.0029

Morgan, P. S., Guo, Z., \& Hayford, S. R. (2009). China's below-replacement fertility: Recent trends and future prospects. Population and Development Review, 35, 605-629. https://doi.org/10. 1111/j.1728-4457.2009.00298.x

Newman, L. A., \& Hugo, G. J. (2006). Women's fertility, religion and education in a low-fertility population: Evidence from South Australia. Journal of Population Research, 23(1), 41-66. https:// doi.org/10.1007/BF03031867

Niu, J. L., \& Qi, Y. Q. (2019). The educational differential in fertility in transitional China: Temporal and regional variation. Demographic Research, 42, 657-688. https://doi.org/10.4054/DemRes. 2020.42 .22 
Padmadas, S. S. (2017). Two-child policy in China: Rhetoric versus reality. Annals of Human Biology, 44(2), 97-98. https://doi.org/10.1080/03014460.2016.1177113

Perkin, D., \& Yusuf, S. (1984). Rural development in China. Maryland, Johns Hopkins University Press.

Poston, D. L. (2000). Social and economic development and the fertility transitions in mainland China and Taiwan. Population and Development Review, 26(S), 40-60. https://www.jstor.org/stable/31152 11. Accessed 7 Oct 2021.

Poston, D. L., \& Gu, B. (1987). Social economic development, family planning and fertility in China. Demography, 24, 531-551. https://doi.org/10.2307/2061390

Qin, M. (2016). Evolution of family planning policy and its impact on population change in china. Unpublished PhD thesis, Social Statistics and Demography, University of Southampton.

Qin, M., Falkingham, J., \& Padmadas, S. S. (2018). Unpacking the differential impact of family planning policies in China: Analysis of parity progression ratios from retrospective birth history data, 19712005. Journal of Biosocial Science, 15, 10. https://doi.org/10.1017/S002193201700061X ahead of print.

Retherford, R. D., Choe, M. K., Chen, J. J., Li, X. R., \& Cui, H. Y. (2005). How far has fertility in China really declined? Population and Development Review, 31, 57-84. https://doi.org/10.1111/j.17284457.2005.00052.x

Retherford, R. D., Ogawa, N., Matsukura, R., \& Eini-Zinab, H. (2010). Multivariate analysis of parity progression-based measures of the total fertility rate and its components using Individual-Level Data. Demography, 47(1), 97-124. https://doi.org/10.1353/dem.0.0087

Robinson, W. C., \& Ross, J. A. (2007). The global family planning revolution: Three decades of population policies and programs. The International Bank for Reconstruction and Development/ The World Bank.

Singer, J. D., \& Willett, J. B. (2003). Applied Longitudinal Data Analysis: Modelling change and event occurrence. Oxford University Press.

Smith, H. L. (1989). Integrating theory and research on the institutional determinants of fertility. Demography, 26, 171-184. https://doi.org/10.2307/2061518

StataCorp. (2011). Stata 12 base reference manual. Stata Press.

Tien, X. Y. (1980). Wan, Xi, Shao: How China meets its population problem. International Family Planning Perspectives, 6, 65-70. https://doi.org/10.2307/2947873

Tien, X. Y. (1984). Induced fertility transition: Impact of population planning and socio-economic change in the people's republic of China. Population Studies, 38(3), 385-400. https://doi.org/10.2307/ 2174130

Tsang, M. C. (2000). Education and national development in China since 1949: Oscillating policies and enduring dilemmas. China Review, pp. 579-618. https://www.jstor.org/stable/23453384. Accessed 7 Oct 2021.

United Nations. (1987). A comparative evaluation of data quality in thirty-eight World Fertility Surveys. United Nations.

United Nations. (1995). Women's education and fertility behaviour: Recent evidence from the Demographic and Health Surveys. United Nations.

Wang, F. (2012). Family planning policy in china: measurement and impact on fertility. MPRA Paper No. 42226, Munich Personal RePEc Archive.

Xing-Yuan, G., \& Tang, S.-L. (1995). Reform of the Chinese health care financing system. Health Policy, 32, 181-191. https://doi.org/10.1016/0168-8510(95)00735-b

Yang, D. T., \& Chen, D. D. (2004). Transformations in China's population policies and demographic structure. Pacific Economic Review, 9(3), 269-290. https://doi.org/10.1111/j.1468-0106.2004. 00248.X

Yeung, Y. M., \& Hu, X. W. (1992). China's coastal cities: Catalysts for modernization. University of Hawai Press.

Zeng, Y., \& Hesketh, T. (2016). The effects of China's universal two-child policy. Lancet, 388(10054), 1930-1938. https://doi.org/10.1016/S0140-6736(16)31405-2

Zhang, J. (1990). Socioeconomic determinants of fertility in China: A microeconometric analysis. Journal of Population Economics, 3(2), 105-123. https://doi.org/10.1007/BF00187287

Zheng, Z. Z. (2004). Fertility desire of Chinese women. Chinese Journal of Population Science, 5, 73-80. (in Chinese). 
Zheng, Z. Z., Cai, Y., Wang, F., \& Gu, B. (2009). Below-replacement fertility and childbearing intention in Jiangsu Province, China. Asian Population Studies, 5(3), 329-347. https://doi.org/10.1080/17441 730903351701.

Zhuang, Y. E., Jiang, Y., \& Li, B. (2020). Fertility intention and related factors in China: Findings from the 2017 National Fertility Survey. China Population and Development Studies, 4, 114-126. https:// doi.org/10.1007/s42379-020-00053-7.

Zhuang, Y. E., Jiang, Y., Wang, Z. L., Li, C. F., Qi, J., Wang, H., Liu, H., Li, B., \& Qin, M. (2014). Fertility intention of rural and urban residents in china: Results from the 2013 national fertility intention survey. Population Research, 38(3), 3-13. (in Chinese).
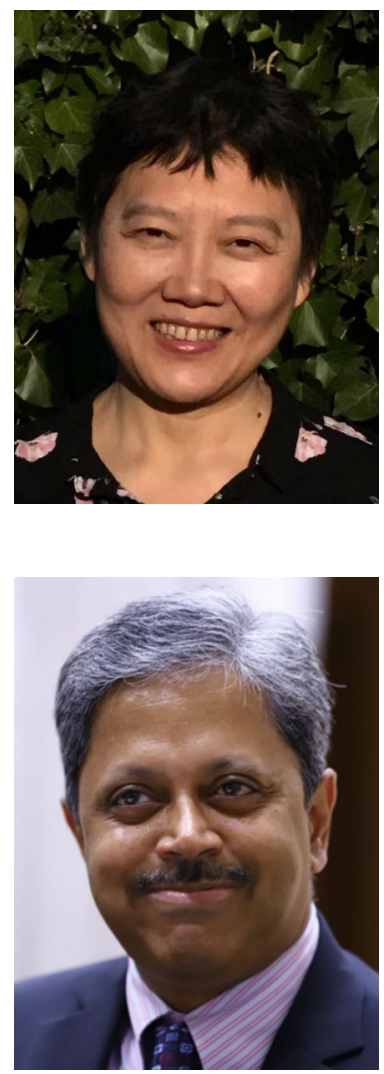

Dr Min Qin is a researcher at ESRC Centre for Population Change, Centre for Research on Ageing, University of Southampton, UK, and China Population and Development Research Centre, China. Her research interests include population change, intergenerational support, and population health.
Sabu S. Padmadas is Professor of Demography and Global Health at the Department of Social Statistics and Demography and Founding Co-Director of the Centre for Global Health, Population, Poverty and Policy (GHP3) at the University of Southampton. His research interests focus broadly on population dynamics and the application of demographic analysis and statistical modelling of global health and wellbeing outcomes in low-middle income and transition economies, with a focus on China and India. 


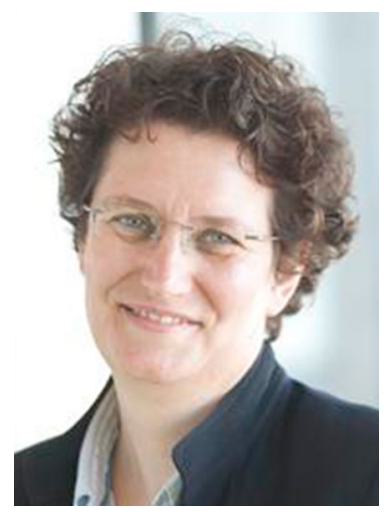

Professor Jane Falkingham is currently the Director of the ESRC Centre for Population Change, and a member of ESRC Council in the UK. She was President of the European Association of Population Studies (EAPS) (2018-2020) and President British Society for Population Studies (2016-2018). Her research interests are in: The drivers and consequences of population change, both in the UK and internationally; Ageing, intergenerational relations and the changing life course; Population ageing and social security, in particular the design of pensions systems and their impact upon resources in later life; The redistributive effect of the welfare state, in particular how it varies both across the life-cycle for an individual and also between cohorts with changes in the life course.

\section{Authors and Affiliations}

\section{Min Qin ${ }^{1,2}$ (D) Sabu S. Padmadas ${ }^{4}$ Jane Falkingham ${ }^{3}$}

Sabu S. Padmadas

S.Padmadas@soton.ac.uk

Jane Falkingham

J.C.Falkingham@soton.ac.uk

1 ESRC Centre for Population Change, Centre for Research on Ageing, School of Economic, Social and Political Sciences, University of Southampton, Highfield Campus,

Southampton SO17 1BJ, UK

2 China Population and Development Research Center, Beijing, China

3 ESRC Centre for Population Change and China Research Centre, School of Economic, Social and Political Sciences, University of Southampton, Southampton, UK

4 Department of Social Statistics and Demography and China Research Centre, School of Economic, Social and Political Sciences, University of Southampton, Southampton, UK 